\title{
RESIDUOS DE ETHION E FENITROTHION EM CASCAS E POLPAS DE LARANJAS HAMLIN DETERMINADOS POR CROMATOGRAFIA EM FASE GASOSA
}

\author{
RENE LUISS DE OLIVEIRA RIGITANO
}

Orientador: GILBERTO CASADEI DE BATISTA

Dissertação apresentada à Escola Superior de Agricultura "Luiz de Queiroz", da Universidade de São Paulo, para obtenção do título de Mestre em Entomologia.

\footnotetext{
$P|R A C| C A B A$

Estado de São Paulo - Brasil

Agosto, 1979
} 
A Cristina, minha noiva e

a meus irmãos Viviana, Marcel e Odilamar

OFEREÇO

A meus pais Luiz e Odila que, com muito amor, não mediram esforços para que eu chegasse atē esta etapa de minha vida 


\section{AGRADECIMENTOS}

Ao Prof. Dr. Gilberto Casadei de Batista, pela orientação, dedicação e estỉmulo.

Ao Dr. Joaquim Teōfilo Sobrinho, Chefe da Estação Experimental de Citricultura do Instituto Agronómico de Campinas, pela sua receptividade e apoio.

Ao Engl Agro M.S. Clovis Ribas, da Estação Experimental de Manduri do Instituto Florestal de São Paulo pelas sugestões apresentadas.

Ao Eng? Agrọ José Luiz Gaiad de Camargo, pela colaboração na realização de parte deste trabalho.

A Coordenação do Aperfeiçoamento de Pessoal de Nível Superior-CAPES, pela concessão de bolsa de estudos.

Ao Conselho Nacional de Desenvolvimento Cientifico e Tecnolōgico-CNPq, atravēs do Programa Integrado de Pesquisa em Parasitologia Agrícola; pelo apoio financeiro concedido. 
Ao Prof.Dr. Evôneo Berti Filho pela correção do "sumnary". Ao Prof. Dr. Domingos Gallo, Chefe do Departamento de Entomologia da ESALQ-USP, demais professores, funcionārios e colegas, pelo incentivo e apoio recebidos.

Ao Prof. Dr. Octávio Nakano, pelo acolhimento junto ao Departamento e apoio constante.

A Bayer do Brasil S.A. pela concessão de recursos para a impressão do presente trabalho.

A Srta. Odette Simão, bibliotecāria-chefe da ESALQ-USP, pela ajuda nas citações bibliogrāficas.

A Sra. Elisa da Silva Peron, pelos serviços de datilografia. 


\section{INDICE}

Pāgina

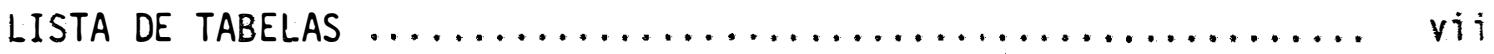

LISTA DE FIGURAS $\ldots \ldots \ldots \ldots \ldots \ldots \ldots \ldots \ldots \ldots \ldots \ldots \ldots \ldots \ldots \ldots \ldots \ldots \ldots$

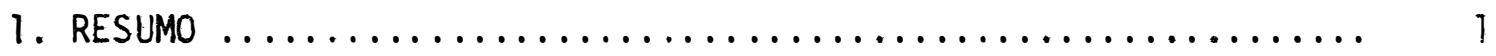

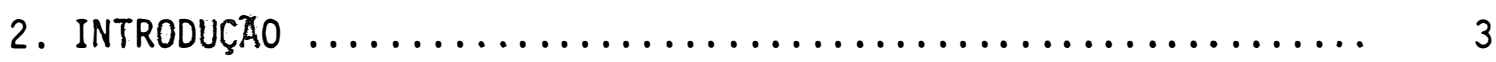

3. REVISAO DE LITERATURA $\ldots \ldots \ldots \ldots \ldots \ldots \ldots \ldots \ldots \ldots \ldots \ldots \ldots$

3.1. Depōsito, penetração e persistência de pesticidas ...... 6

3.2. Comportamento dos residuos de alguns pesticidas em frutas citricas .............................. 13

3.3. Residuos de pesticidas em produtos citricos .......... 19 3.3.1. Sucos de frutas citricas .................. 19

3.3.2. Rações para gado $\ldots \ldots \ldots \ldots \ldots \ldots \ldots \ldots \ldots \ldots . .22$

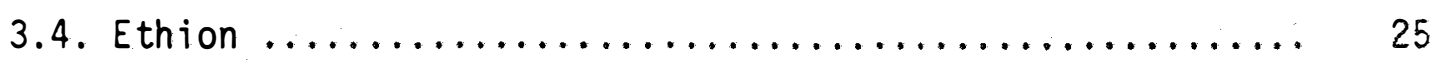

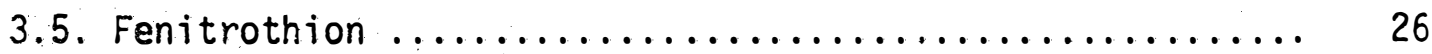

3.6. Comportamento dos residuos de ethion e fenitrothion em algumas culturas ............................ 27

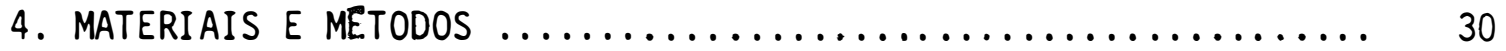

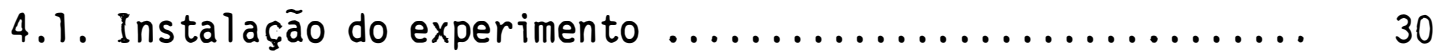

4.2. Limites de detecção, porcentagens de recuperação e descrição do método de anālise de resĩduos ........... 32

4.2.1. Reagentes ........................... 33

4.2.2. Apare Thos, vidraria e outros materiais ........ 33

4.2.3. Marcha analitica ....................... 34 
Pāgina

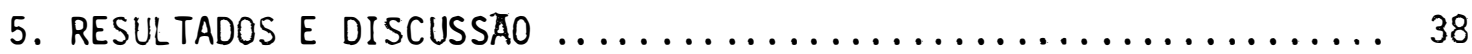

5.1. Limites de detecção e porcentagens de recuperação do método ...................................... 38

5.2. Residuos de ethion e fenitrothion nas cascas e pol-

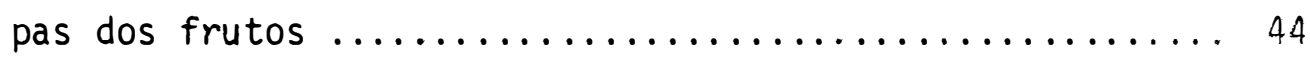

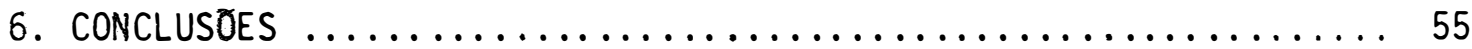

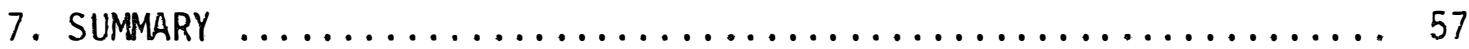

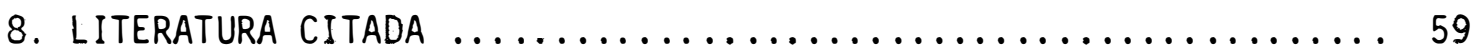




\section{LISTA DE TABELAS}

Tabela nọ

Pāgina

1 Valores de meia-vida de persistência, em dias, de alguns pesticidas sobre e no interior de cascas de frutas citricas tratadas no campo ............. 12

2 Resĩduos de alguns inseticidas em sucos de fru-

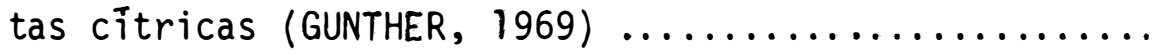

3 Resíduos de pesticidas em rações para gado, preparadas no laboratório, a partir de cascas e bagaço de frutas citricas provenientes de plantas que receberam tratamentos comerciais (GUNTHER,

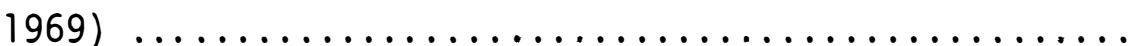

4 Porcentagens de recuperação de ethion e fenitrothion pelo método de MöLLHOFF (1967) de cascas e polpas de laranja fortificadas .............. 38

5 Resíduos de ethion, expressos em ppm, na casca e na polpa de frutos de laranja provenientes de plantas pulverizadas com $400 \mathrm{ml}$ de Ethiol 100 (10\% de ethion mais $68 \%$ de ōleo mineral) por 100

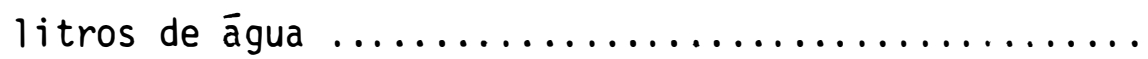

6 Resíduos de fenitrothion, expressos em ppm, na casca e na polpa de frutos de laranja provenien tes de plantas pulverizadas com $150 \mathrm{ml}$ de Folithion 50 C.E. por 1001 itros de àgua ............. 47

7 Peso de cascas e polpas de amostras de laranjas Hamlin em estāgio de maturação ................. 54 
Figura $n$ ?

1 Demonstração grāfica do comportamento idealizado dos residuos de dieldrin e chlorfenson em frutas citricas (GUNTHER e BLINN, 1956) .............

2 Curvas de degradação e persistência, idealizadas e ilustrativas, para inseticidas não sistêmicos sobre e no interior das cascas de laranjas Valência (GUNTHER, 1969). O exemplo para ma lathion (dosagem: 3 1D PM 25\%/100 gal) foi extraido pelo autor de GUNTHER e WESTLAKE (1968) ....... 10

3 Curvas de degradação e persistência de ethion sobre e no interior das cascas de limões siciliano e laranjas Valência; dosagens: 1 lb de i.a. (25\% PM)/100 gal, 1500 gal/acre para 1imões e 2500 gal/acre para laranjas (GUNTHER et alii, 1962) $\ldots \ldots \ldots \ldots \ldots \ldots \ldots \ldots \ldots \ldots \ldots \ldots . .6 \ldots$

4 Fórmula plana do ethion $\ldots \ldots \ldots \ldots \ldots \ldots \ldots \ldots \ldots . .26$

5 Fórmula plana do fenitrothion $\ldots \ldots \ldots \ldots \ldots \ldots \ldots . . \ldots$

6 Foto mostrando o tamanho das ārvores de laranja utilizadas no presente trabalho, assim como 0 estāgio de maturação dos frutos 45 após a aplicação .................................. 31

7 Cromatogramas da fortificação de $0,01 \mathrm{ppm}$ de ethion em cascas ........................... 41

8 Cromatogramas da fortificação de $0,05 \mathrm{ppm}$ de ethion em polpas ........................... 42 
Figura nọ

9 Cromatogramas da fortificação de $0,05 \mathrm{ppm}$ de

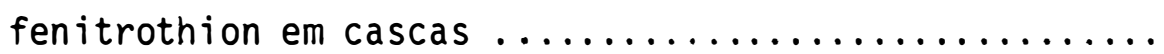

10 Cromatogramas da fortificação de 0,05 ppm de

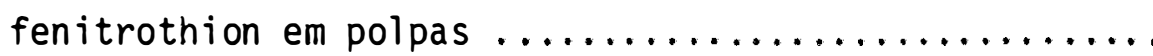

11 Curvas de degradação e persistência de resîduos de ethion sobre e no interior de cascas de laranjas Hamlin provenientes de plantas pulverizadas com $400 \mathrm{ml}$ de Ethiol 100 por 100 litros de àgua

12 Curvas de degradação e persistência de resîduos de fenitrothion sobre e no interior de cascas de laranjas Hamlin provenientes de plantas pulverizadas com $150 \mathrm{ml}$ de Folithion

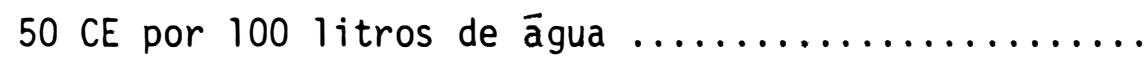


1. RESUMO

Objetivou-se no presente trabalho estudar a persistēncia dos residuos de ethion (Ethiol 100: 10\% de ethion mais 68\% de ōleo mineral) e fenitrothion (Folithion $50 \mathrm{CE}$ ) em cascas e polpas de frutas $\mathrm{C}$ itricas.

0 experimento foi instalado em pomar de laranjas da variedade Hamlin, com sete anos de idade, localizado na Estação Experimental de Citricultura do Instituto Agronōmico de Campinas, em Cordeirópolis, SP.

Por ocasião do inīcio de maturação dos frutos foi realizada a aplicação dos produtos nas dosagens de $400 \mathrm{ml}$ de Ethiol 100 e $150 \mathrm{ml}$ de Folithion 50 CE por 1001 de àgua, ou ainda, 0,68 ml de i.a.de ethion e $1,275 \mathrm{ml}$ de i.a. de fenitrothion por planta, com auxilio de um pulverizador costal motorizado. Os frutos foram amostrados e analizados aos 3,10,17,24,34,45, 60 e 104 dias apōs a aplicação, sendo as cascas e as polpas analizadas separadamente.

0 mētodo empregado nas anālises foi adaptado de MöLLHOFF (1967), e constou de extração com acetona e purificação atravēs de 
partição em clorofórmio. A limpeza do extrato foi efetuada em coluna de florisil e a eluição procedida com benzeno. o extrato assim purificado doi concentrado e injetado em cromatógrafo a gás marca CG-modelo 3700 ,equipado com coluna de vidro (1,8 m de comprimento e 1/8" de diāmetro) em pacotada com 10\% DC 200/chromosorb W silanizado e detector de ionização de chama alcalina (DICA). Esta metodologia proporcionou limites de detec ção de 0,01 ppm em cascas e polpas para ethion e 0,05 e 0,02 ppm para fe nitrothion, respectivamente. As porcentagens de recuperação em amostras fortificadas a diferentes concentrações variaram de 92 a 104\% para ethion e 82 a $102 \%$ para fenitrothion.

As anālises de cascas revelaram que os resíduos de fenitrothion são mais persistentes que os de ethion, como mostram os valores de meia-vida de persisténcia encontrados, ou seja, 89 e 50 dias, respectivamente.

Não foram detectados resíduos desses pesticidas nas polpas dos frutos durante o período de estudo, mostrando muito pouca, talvez ausente, penetração dos residuos nas partes comestiveis dos frutos.

Com base nos resultados obtidos e nos limites de tolerância para esses produtos em frutas citricas estabelecidos pelo Grupo de Trabalho - GT 2, da Comissão Nacional de Normas e Padrões para Alimentos do Ministērio da Saūde, os resīduos de fenitrothion, com base na fru ta toda, baixaram atē o limite de tolerância $(0,4 \mathrm{ppm})$ oito dias apōs a. aplicação, enquanto os de ethion não foram superiores ao limite de tolerāncia (2 ppm, com base na fruta toda) desde a primeira amostragem, ou seja, aos três dias apōs a aplicação. 


\section{INTRODUÇAO}

$\mathrm{Na}$ luta da humanidade contra as pragas das plantas cultivadas, adotam-se vários métodos bastante eficazes que, individualmente ou associados no controle integrado, conseguem reduzir a baixos niveis os prejuízos causados à indústria agrícola. No entanto, o uso isolado dos chamados defensivos químicos ou pesticidas tem sido o principal recurso utilizado pelos lavradores de todo o mundo para lines assegurar 0 rendimento de suas lavouras.

Segundo recente comunicaçào à American Association for the Advancement of Science, o Dr. John C. Headley espera que nos Estados Unidos os pesticidas estejam, ainda nos próximos quinze anos, a desempenhar importante papel no controle de pragas, doenças e ervas daninhas (AMERICAN CHEMICAL SOCIETY, 1979).

Indubitavelmente, o uso de substâncias quĩmicas concorre para aumentar a produção agrīcola, mas, por outro lado, $\bar{e}$ passivel de acarretar a persistência de resỉduos tóxicos nas partes tratadas, cujo consumo, mesmo em pequenas doses sub-letais, representa um grave risco potencial à saūde dos consumidores. 
Sendo o Brasil um paîs no qual mais da metade de sua receita cambial advēm das exportações de produtos agrīcolas (café, soja, cacau, produtos citricos, etc.), o problema de residuos nestes produtos é particular e potencialmente importantissimo, uma vez que poderão ser criadas dificuldades às nossas exportações, devido à presença de resīduos tōxicos em nossos produtos, pois, as nações importadoras se vēem no direito de rejeitar os produtos adquiridos com resíduos acima do limite de tolerância, como aconteceu em 1971, com partilhas de carne e fumo, ex portados pelo Brasil, que foram recusadas pelos Estados Unidos e Alemanha Ocidental, com altos teores de lindane e BHC, respectivamente.

De 1974 a 1976 houve aumento substancial nas exportações brasileiras de suco concentrado de frutas citricas (BRASIL. Fund. IBGE, 1977), mostrando um aumento na demanda mundial e, consequentemente, uma fonte bastante promissora de divisas para o nosso pais.

No processamento industrial para a obtenção de sucos concentrados de frutas citricas, tem-se como subprodutos as cascas e bagaços dos frutos que, apōs algum processamento, são tambēm utilizados como raçào para gado. Assim, é de suma importāncia o conhecimento sobre o comportamento de residuos de pesticidas tanto na polpa (parte comestîvel) como nas cascas de frutas citricas.

No Brasil, o limite de tolerāncia e perīodo de carência estabelecidos para residuos de pesticidas, de acordo com a cultura são, na grande maioria dos casos, baseados em trabalhos realizados no exterior. Uma vez que as condições climāticas, diferenças varietais, tioo 
de formulação empregada, etc. são fatores que afetam grandemente 0 comportamento de residuos de pesticidas em frutas citricas (GUNTHER, 1969), estudos desse tipo são necessārios para as nossas condições.

Os objetivos pretendidos no presente trabalho foram os se guintes:

a) estudo sobre a persistēncia de resĩduos de ethion e fe nitrothion em cascas e polpas de laranjas Hamlin;

b) estabelecimento de curvas de degradação desses pesticidas naqueles substratos;

c) correlação entre os niveis de residuos encontrados com os limites de tolerância e os períodos de caréncia estabelecidos pela lei. 


\section{REVISAOO DE LITERATURA}

\subsection{Depōsito, penetração e persistência de pesticidas.}

Segundo GUNTHER (1969), depósitos e resíduos de pesticidas orgānicos não são termos sinōnimos. A palaura "depósito" refere-se ao produto inicialmente colocado sobre a superfície da planta pelo tratamento, enquanto que a palavra "resĩduo" refere-se ao produto com a im plicação do envelhecimento pelo tempo decorrido do tratamento e/ou alteração, independentemente do local, ou seja, sobre ou no interior das foThas ou frutos. Desse modo, um depósito torna-se um resĩduo, assim que ele é afetado pela ação de agentes atmosfēricos, conversões metabōlicas ou outros processos que causam alteração, degradação, formação de comple xos ou ainda, migração. As grandezas dos depósitos iniciais são influen ciadas por muitos fatores, incluindo natureza e dosagem do produto, composição da formulação, mētodo e uniformidade de aplicação, diferenças va rietais entre as árvores, diferenças ambientais, diferenças sasonais e* outras. Esses depósitos normalmente consistem de camadas de material fra camente ligado. Somente a camada mais inferior liga-se firmemente à superficie da planta pelas propriedades adesivas da formulação e pela 
estrutura química e física da superfície da planta.

De acordo com GUNTHER e BLINN (1956), assim que o material depositado não aderido firmemente à superfície do fruto (ou folha) se desprende, a porção remanescente do depósito inicial torna-se uma por ção estabilizada de um depósito efetivo (em termos de eficiência biológica para o controle de pragas), seguindo-se um residuo efetivo conforme se inicia a penetração na casca ou ainda, um resíduo penetrado, pela extensa migração no interior (e talvez através) da casca, como ilustrado esquematicamente na Figura 1. A parte da curva designada como $X$ representa fisicamente 0 produto deslocado pelo desprendimento das camadas superiores fracamente ligadas do depósito inicial, principalmente pela ação dos ventos; Y representa uma curva de degradação tỉpica de ações combinadas de desprendimento, codestilação associada com o processo de respiração da planta, volatilização, fotodecomposição, hidrōlise, oxidação e penetração; $Z$ representa uma curva de persistência do material pe netrado, o qual é agora sujeito somente ao ataque metabōlico e hidrolítico. Tais curvas idealizadas obviamente representam somas desses e tal vez outros processos atuando simultaneamente com transiçōes graduais de um estágio para outro.

Desde que frutas cîtricas têm essencialmente superfícies cerosas descontinuas, produtos solūveis podem se dissolver nos componentes cerosos e oleosos da casca, onde eles podem ficar imutāveis por longos periodos (GUNTHER, 1969). 

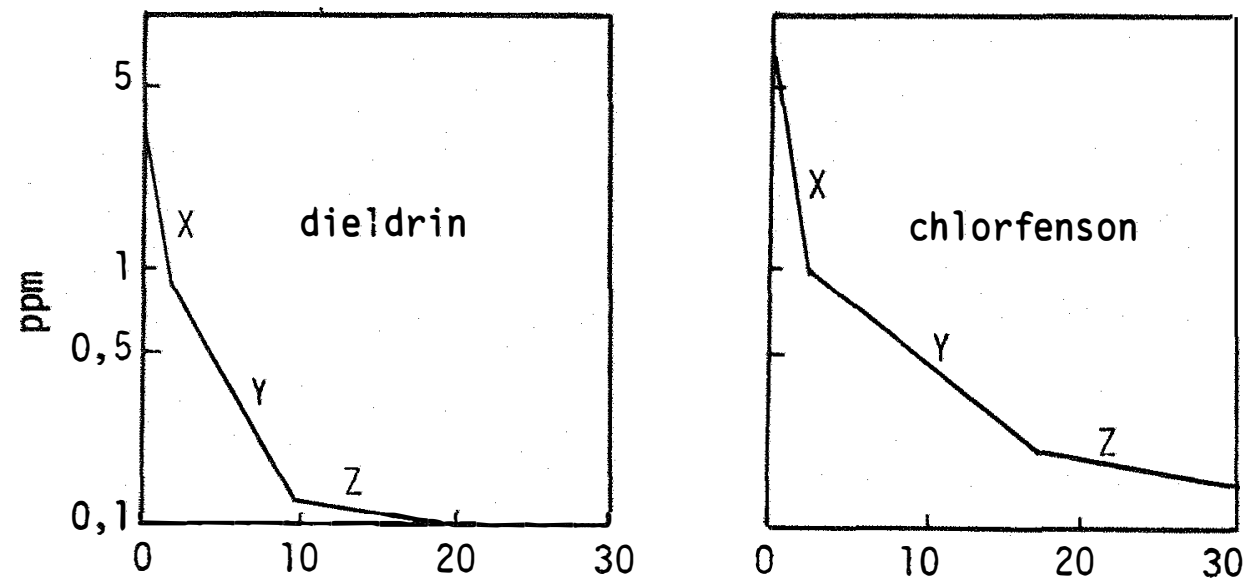

Dias apōs a aplıcação

Figura 1. Demonstração grāfica do comportamento idealizado dos resĩduos de dieldrin e chlorfenson em frutas cîtricas (GUNTHER e BLINN, 1956)

Residuos penetrantes e degradantes (Y na Fig. I) tendem a desaparecer ou degradar em taxas, para cada composto e cada variedade, as quais são, aproximadamente, funções diretas das concentrações aplicadas dos produtos. Entretanto, a porcentagem ou decréscimos fracionais dos resĩduos, com o tempo, são independentes, tanto da concentração inicial como das grandezas do depōsito. Do mesmo modo, os resíduos persistentes (Z) também desaparecem ou são degradados a uma taxa constante, pọ rém, mais vagarosa para cada composto e algumas vezes para cada variedade (GUNTHER e BLINN, 1955).

Segundo GUNTHER (1969), os processos de degradação e persistência geralmente seguem uma reação cinētica de primeira ordem. Assim, curvas de degradação e persistência para um composto específico podem 
ser plotadas semilogaritmamente como linhas retas do logarítmo do valor do residuo (em $\mathrm{ppm})$, contra o tempo decorrido desde o tratamento, como mostrado anteriormente na Figura 1 e exemplificado na Figura 2 . Os residuos na casca de frutas citricas, geralmente exibem um comportamento curvilineo não simétrico em escala aritmética e duas interessantes curvas ( $B$ e C) em escala semilogaritmica. A curva B é a curva de degradação e a $C$, a de persistēncia. A curva B representa o desaparecimento do produto inicialmente aplicado, ainda parcialmente na superfície, pelos processos de perda do depósito, ação de fatores atmosféricos e ataque metabōlico; enquanto que a curva C representa o produto persistente, mas a inda vagarosamente degradado, que penetrou internamente às camadas cut culares mais externas e é afetado apenas por ataque metabōlico por agentes no interior dos tecidos da casca.

Segundo EBELING (1963), citado por RIBAS (1976), os fatores envolvidos no desaparecimento dos residuos de pesticidas podem ser divididos em dois grupos. No primeiro estão aqueles comuns a todos os pesticidas e são a natureza da planta tratada - as características físicas de sua superfície e seu grau de desenvolvimento; a natureza da formulação do pesticida - grau e intensidade de penetração ou a tenacidade de seu depósito inicial; fatores que provocam a remoção dos depōsitos su perficiais, tais como chuva, vento, luz umidade e ação mecânica. Esses fatores possuem grande influēncia nas fases de resĩduo/indicadas graficamente como X e Y na Figura 1. Suas influências decrescem rapidamente após a eliminação dos depósitos iniciais embora alguns fatores como a temperatura e a luz continuem agindo durante todo o tempo. No segundo 
grupo, estão os fatores dependentes da natureza do produto, incluindo vo latilização e decomposição quỉmica./ Esses fatores afetam o desaparecimento dos residuos nas fases $X, Y$ e $Z$. Muitos pesticidas podem penetrar no tecido da planta e serem metabolizados ou então quimicamente alterados, afetando a quantidade e a persistência dos residduos.

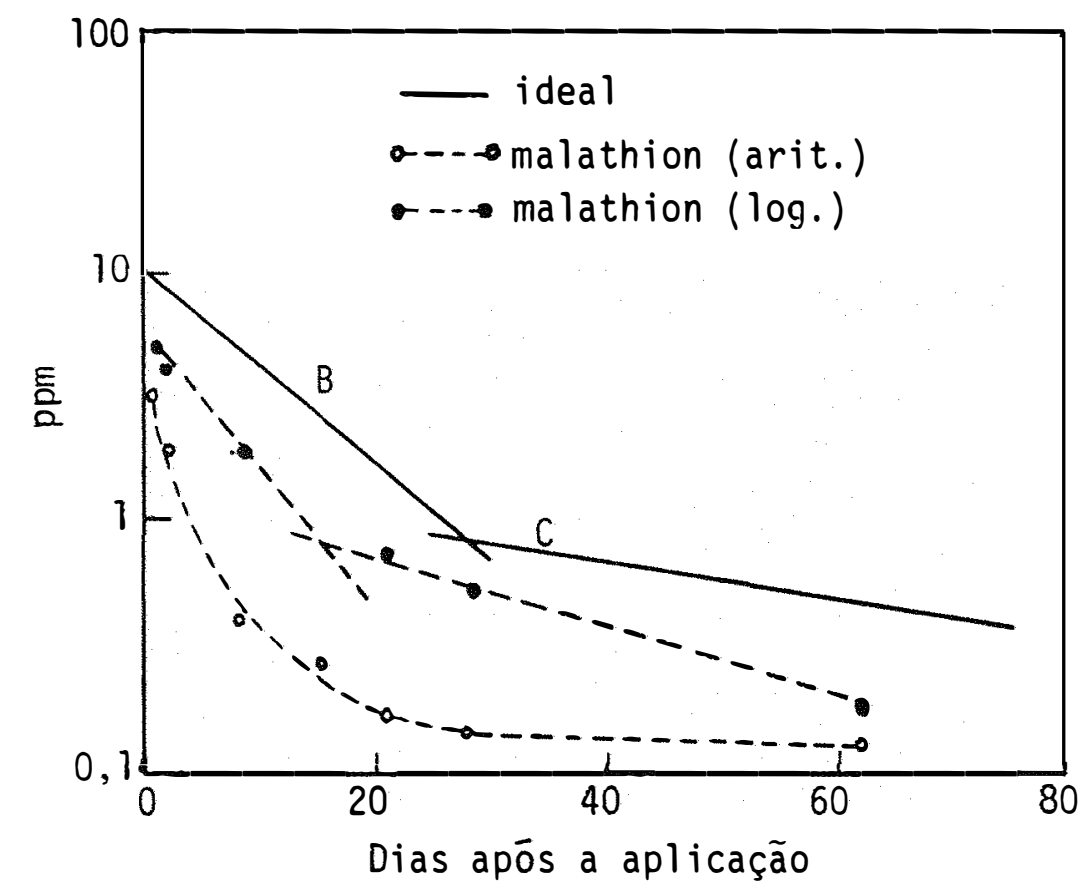

Figura 2. Curvas de degradação e persistência, idealizadas e ilustrativas, para inseticidas não sistêmicos sobre e no interior das cascas de laranjas Valēncia (GUNTHER, 1969). O exemplo para malathion (dosagem: 3 ID PM 25\%/100 gal) foi extraido pelo au tor de GUNTHER e WESTLAKE (1968)

* Uma das determinações importantes no estudo de resíduos de pesticidas é sem dúvida o valor da meia-vida de persistência dos mesmos. Segundo GUNTHER e BLINN (1955), meia-vida é usualmente definido co mo o tempo requerido para a metade de uma dada quantidade de material 
reagir (ou dissipar). Para um determinado composto em uma dada cultura, a meia-vida de persistência representa uma caracteristica surpreendentemente constante e um valor útil em comparações da persistência (longevidade) de vários pesticidas em uma cultura particular.

Para ilustrar o intervalo de persistência comumente encontrado, na Tabela 1 estão listados alguns valores de meia-vida de persistência, em dias, de alguns inseticidas em cascas de frutas citricas.

0 assunto referente à penetração foi estudado também por GUNTHER e JEPPSON (1954) e por GUNTHER e BLINN (1955) que distinguiram três categorias de resíduos assim designados: extracuticular, cuticular e subcuticular. O primeiro ē o resīduo aderente à camada de cera (depósito superficial); o segundo é o resỉduo incrustado ou dissolvido nela e o terceiro é aquele presente abaixo desta camada. 
Tabela 1. Valores de meia-vida de persistência, em dias, de alguns pesticidas sobre e no interior de cascas de frutas cítricas tratadas no campo

\begin{tabular}{|c|c|c|c|}
\hline Pesticida & Laranjas & Limões & Referência \\
\hline azinphos methyl & 355 & 38 & $\begin{array}{l}\text { GUNTHER et alii. (1963) citados por } \\
\text { GUNTHER } \\
\text { (1969). }\end{array}$ \\
\hline carbophenothion & 42 & 22 & GUNTHER et alii. (1959) \\
\hline chlordane & - & 19 & BLINN et alii (1959) \\
\hline chlorobenzilate & - & 70 & GUNTHER et alii. (1955) \\
\hline diazinon & 17 & 13 & $\begin{array}{l}\text { GUNTHER et al ij (1958) citados por } \\
\text { GUNTHER }\end{array}$ \\
\hline dicofol & 200 & 125 & GUNTHER et alii. (1957) \\
\hline dicrotophos & 15 & - & $\begin{array}{l}\text { MURPHY et alii (1965) citados por } \\
\text { GUNTHER (1969) }\end{array}$ \\
\hline dieldrin & - & 60 & BLINN et alii. (1959) \\
\hline dime thoate & 19 & - & $\begin{array}{l}\text { GUNTHER et alii. (1965) citados por } \\
\text { GUNTHER }\end{array}$ \\
\hline ethion & 42 & 30 & GUNTHER et alii (1962) \\
\hline heptachlor & - & 23 & BLINN et alii. (1959) \\
\hline malathion & 32 & - & BLINN et alii (1959) \\
\hline monocrotophos & 13 & - & WESTLAKE et alii (1970) \\
\hline phenthoate & 50 & 100 & IWATA et alii. (1977) \\
\hline propargite & 80 & 50 & WESTLAKE et alii (1971) \\
\hline
\end{tabular}


3.2. Comportamento dos residuos de alguns pesticidas em frutas citricas

0 interesse na obtenção de dados a respeito de resíduos de inseticidas e acaricidas em frutas cîtricas é relativamente antigo em outros paises, principalmente nos Estados Unidos.

Segundo GUNTHER (1969), os primeiros estudos de desaparecimento do depósito e resīduos de pesticidas foram desenvolvidos com ava liações dos resĩduos de DDT em folhas e cascas de frutas cittricas por F.A.Gunther em 1945 e 1946.

Devido a dificuldades, principalmente de ordens experimen tais, dados concretos sobre o comportamento de pesticidas em frutas cítricas não foram obtidos até o momento entre nōs.

Residuos de dicofol foram determinados em cascas e polpas de laranjas Valência, limões siciliano e em rações para gado fabricadas com essas frutas por GUNTHER et alii. (1957). A persistência desses residuos pode ser ilustrada pelos valores $\mathrm{RL}_{50}$ (meia-vida de persistência) de 170 a 350 dias para laranjas e 120 a 150 dias para limões. As comparações das grandezas dos resĩduos obtidos simultaneamente por três métodos indicaram pouca degradação metabōlica no fruto. Quantidades inexpressivas foram encontradas nas partes comestiveis dos frutos. As cascas retiveram aproximadamente $30 \%$ dos residuos de dicofol após serem pro cessadas em ração para gado. Os estudos ainda incluĩram determinações em laranjas làvadas e não lavadas colhidas em vārias épocas $(1,5,11$, 
$15,24,43,78$ e 103 dias) após o tratamento com 1,6 1b do dicofol PM $25 \%$ e 0,4 gal do CE $25 \%$ por 100 gal de água. As laranjas que foram lavadas numa solução detergente, antes de serem descascadas, mostraram que o dicofol penetra vagarosamente nas porções oleosas e cerosas da casca, sendo os residuos exocuticulares e depósitos oriundos das duas formulações reduzidos por lavagem até os 40 dias após o tratamento.

GUNTHER et alii (1955) estudaram a persistência de chlorobenzilate em limões siciliano com a aplicação de 1 e 3 lb de uma formulação PM 25\% por 100 galões. Os frutos foram colhidos aos 2, 4, 8, 15, 29, 64, 90, 120 e 141 dias apōs o tratamento e os residuos foram analisa dos por dois métodos diferentes. Os frutos foram lavados, descascados e processados. Os resultados obtidos mostraram que 0 chlorobenzilate possui uma meia-vida de 60 a 80 dias sob condições de campo na casca dos limões pulverizados e que 0 acaricida não penetra em quantidades apreciāveis na polpa dos frutos.

A degradação e a persistência de malathion foram investigadas em cascas e polpas de laranjas Valência por BLINN et alii. (1959). 0 inseticida foi aplicado na razão de 3 lb do produto comercial PM 25\% por 100 galões em aplicação a alto volume. As amostras foram colhidas aos $1,2,7,14,21,28$ e 62 dias após aplicação, sendo as cascas e polpas analizadas por método colorimétrico. 0 valor de meia-vida de persis tência nas cascas foi de 32 dias e os residuos encontrados nas polpas fo. ram considerados despreziveis.

GUNTHER et alii. (1962) estudaram a degradação e a persistência de residuos de ethion em cascas de limões siciliano e de laranjas 
Valência. 0 pesticida foi aplicada em dosagens variadas nas formulações pó molhāvel e concentrado emulsionável mais óleo mineral a alto volume. As amostras de limões foram coletadas aos $5,12,19,33$ e 61 dias apōs a aplicação e as de laranjas aos 1, 7, 14, 21, 30,45,60, 90 e 120 dias, sendo as cascas e polpas dos frutos analisadas separadamente pelo método de absorção no infra-vermelho. Os residuos de ethion tiveram em Timões uma meia-vida de persistência de 30 dias para a formulação pō molhāvel e de 44 dias para a formulação concentrado emulsionável e, em laranjas, esses valores foram 42 e 25 dias, respectivamente. Os niveis de resĩduo em frutas lavadas manualmente em solução detergente, antes do processamento simulando a prática comercial, demonstraram a rápida penetração do produto na casca e a impraticabilidade de remoção do resíduo por lavagem na época da colheita. Baseado neste trabalho, GUNTHER(1969) construiu as curvas de degradação e persistência nas cascas dos dois substratos (Figura 3 ).

A anālise de frutas cîtricas importadas pela Suēcia revelaram, segundo RENVAL (1975), que 4,2\% das amostras analisadas continham nīveis de resĩduos de ethion acima do limite de tolerāncia estabelecido por aquele paîs, ou seja, 0,5 ppm com base na fruta toda.

A degradação e a persistência de carbophenothion foram pesquisadas em cascas de laranjas baianinha e limões siciliano por GUNTHER et alii (1959). 0 inseticida foi aplicado em dosagens variadas nas formulações pó molhável (1, 3 e 6 lb PM 25\% por 100 galões) e concentrado emulsionávèl $(0,6$ lb de i.a. por 100 galões), sendo usados aproximadamente 1500 e 2500 gal/acre para limões e laranjas, respectivamente. 


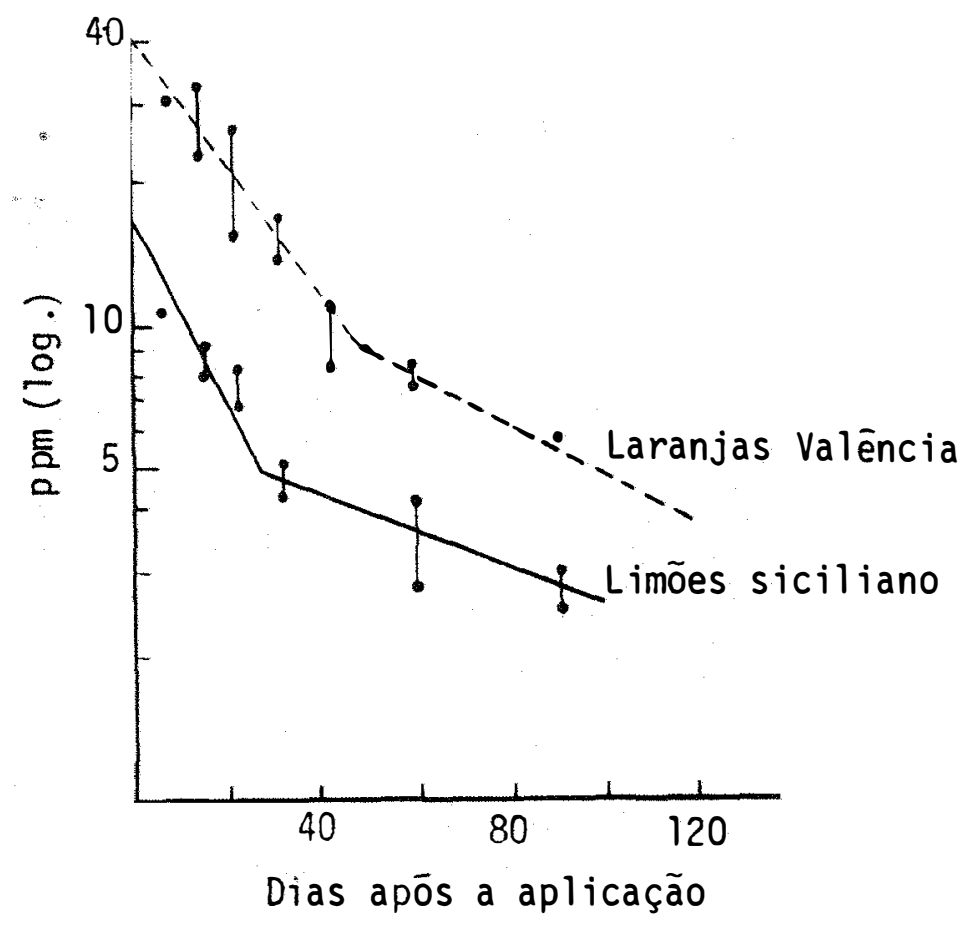

Figura 3. Curvas de degradação e persistēncia de ethion sobre e no interiọ das cascas de limões siciliano e laranjas Valência; do sagens: 1 lb de i.a. (25\% PM)/100 gal, 1500 gal/acre para limões e 2500 gal/acre para laranjas (GUNTHER et alij, 1962)

As amostras de laranjas foram colnidas aos 1, 3, 7, 14, 21, 35, 42, 56 e 70 dias após a aplicação e as de 1 imões aos 1, 6, 9, 15, 23, 29, 43 e 58 dias, as quais foram analisadas por do is métodos diferentes - método colorimétrico e cloro total. A anālise de polpas revelou que o resíduo não excedeu a $0,02 \mathrm{ppm}$ durante 0 perỉodo de estudo.

WESTLAKE et alii. (1970) estudaram a persistência de resīduos de monocrotophos (Azodrin) em laranjas Valéncia e em ração para gado processada no laboratório a partir das frutas tratadas. A meia-vida 
de persisténcia nas cascas das frutas para tratamentos a alto e baixo volumes foram de 13 e 16 dias, respectivamente. A dosagem empregada na aplicação a alto volume foi de 0,5 lb de Azodrin ("technical grade")/ 100 gal e um gasto de aproximadamente 2000 gal/acre, enquanto que na aplicação a baixo volume o mesmo Azodrin foi empregado na razão de l lb/ acre em 100 galões. A lavagem das frutas 12 dias apōs a aplicação teve pequeno efeito sobre os resĩduos, indicando rāpida penetração do inseticida no interior da casca. Não foram encontrados resíduos nas rações pą ra gado processadas no laboratōrio a partir de frutas colhidas 38 dias após a aplicação. Aos 38, 66 e 108 dias, foram analisados os resíduos na polpa das frutas e a aplicação a alto volume resultou em traços do pesticida na parte comestivel da fruta.

0 comportamento dos depósitos e resîduos de phenthoate foi estudado por IWATA et alij. (1977) em laranjas Valência e limões siciliano. 0 produto na formulação concentrado emulsionável foi aplicado na base de 7,5 lb de i.a./acre (100 e 1500 gal/acre para laranjas, 100 e 1250 gal/acre para limões). Outras dosagens utilizadas foram: 3,75 e 1,88 lb de i.a./acre com somente aplicações a alto volume. As amostras foram coletadas aos 3,10, 17, 31, 45 e 56 dias apōs a aplicação e aos 10, 24 e 45 dias foram coletadas amostras que foram submetidas a lavagem no laboratōrio para simular a prātica em "packing house". As amostras foram analisadas por cromatografia gās-līquido usando detector fotométri. co de chama e detector de ionização de chama alcalina.

Esses autores observaram que: 
a) os residuos de phenthoate sobre e no interior das cascas de laranjas dissiparam rapidamente durante um periodo de quatro semanas apōs a aplicação;

b) os valores de meia-vida de persistência encontrados fo ram 50 e 100 dias, para cascas de laranjas e limões, respectivamente;

c) a dissipação em cascas de limões foi qualitativamente semelhante àquela em cascas de laranjas, porēm, mais vagarosa;

d) a aplicação a baixo volume deixou mais resĩduos nas cascas de limões e laranjas em comparação à aplicação correspondente mais diluida;

e) residuos de phenthoate acima de $0,01 \mathrm{ppm}$ não foram encontrados nas polpas de laranjas e limões;

f) o aumento nos níveis de residuos devido à remoção de água no processamento de obtenção de ração para gado foi menor do que 0 esperado, mostrando uma perda aproximada de 44 a $58 \%$ durante o processamento;

g) a anālise de frutas submetidas ao tratamento em "packing house" simulado, mostrou pequena redução nos nỉveis de resíduos. WESTLAKE et alii. (1971) estudaram a persistência de residuos de propargite (Omite) sobre e no interior de laranjas baianinha, li mões siciliano e em rações para gado processadas no laboratōrio a partir de frutas provenientes de plantas tratadas no campo. A meia-vida de per sistência foi aproximadamente 80 e 50 dias para laranjas e limões, 
respectivamente. Os resíduos foram analisados por cromatografia a gás com detector fotométrico de chama. A lavagem dos frutos reduziu de 12 a $20 \%$ os niveis de residuo em amostras de laranjas colhidas aos 7 e 28 dias apōs a aplicação e não houve efeito em amostras colhidas 75 dias apōs. Não houve redução nos resíduos pela lavagem em limões e não houve deteç̧ão de residuos nas polpas de ambas as frutas. Aproximadamente 50\% do residuo nas cascas foi perdido durante o processamento em ração para gado a partir de frutas colhidas 28 dias apōs o tratamento, levando-se em consideração a perda no peso total das cascas devido a perda de água. 0 produto foi aplicado na base de 0,6 lb de i.a./100 gal de calda para ambas as culturas.

ANDERSON et alii. (1963) estudando o efeito do processamento sobre os residuos de azinphos methyl (Guthion) em laranjas, concluiram que cerca de $30 \%$ dos residuos eram removidos pela lavagem dos frutos.

\subsection{Residuos de pesticidas em produtos citricos}

\subsubsection{Sucos de frutas citricas}

As tolerāncias para pesticidas em frutas cîtricas, tanto no mercado interno como no externo, são baseadas na fruta toda. Porém, devido ao interesse dos pesquisadores em avaliar o grau de penetração dos pesticidas nas frutas, as cascas e polpas são separadas e analisadas separadamente. 
Segundo GUNTHER (1969), o residuo encontrado na polpa lavada livre de albedo, pode ser considerado como penetrado no suco, enquanto a fruta estava intacta. Os sucos preparados por meio de prensas mecânicas, rolos conjugados, etc. conterā um pouco dós óleos de citros, que $\bar{e}$ um fator concentrador de resĩduos. Desde que muitos inseticidas são muito solūveis em óleos de citros e uma vez que os resĩduos penetrados desses pesticidas são grandemente encontrados nas bolsas . de óleo da casca, torna-se claro que sucos preparados no laboratörio, apenas separando-se a polpa da casca, devam ser mais isentos de resỉduos de pesticidas do que aqueles preparados por prensas mecânicas. Os dados da Tabela 2, demonstram esta diferença de "contaminação". Os resīduos de DDT e parathion em sucos obtidos por prensas indubitavelmente originamse do óleo, enquanto que 0 de chlorfenson pode ter penetrado na polpa de frutas tratadas.

Porēm, segundo SWISHER (1969) citado por GUNTHER (1969), os extratores de sucos modernos incorporam muito pouco do óleo das cascas e além disso, métodos recentes de processamento de sucos podem envolver (se for o caso) a remoção do óleo por centrifugação a alta velocidade.

Os efeitos da concentração a vācuo (acima de $72^{\circ} \mathrm{Brix}$ ) sobre residuos de pesticidas que podem estar presentes em sucos comerciais não são conhecidos, exceto para parathion (Tabela 2). Pode ser suposto, todavia, que esse processo de destilação a vapor possa remover um pouco dos residuos presentes (GUNTHER, 1969). 
Tabela 2. Residuos de alguns inseticidas em sucos de frutas citricas (GUNTHER, 1969)

\begin{tabular}{|c|c|c|c|c|c|}
\hline \multirow{2}{*}{ Inseticida } & \multirow{2}{*}{ Fruta } & \multirow{2}{*}{$\begin{array}{l}\text { NO de } \\
\text { amostras }\end{array}$} & \multirow{2}{*}{$\begin{array}{c}\text { Modo de } \\
\text { preparaçãa }{ }^{a}\end{array}$} & \multicolumn{2}{|c|}{ Resīduo māximo (ppm) } \\
\hline & & & & Casca $^{b}$ & Suco ${ }^{b}$ \\
\hline aldrin & laranjas & 2 & Com. & - & $<0,1$ \\
\hline Aramite & laranjas & 4 & Com. & - & $<0,1$ \\
\hline \multirow[t]{2}{*}{ azinphos methyl } & limões & 15 & Lab. & 14 & $<0,1$ \\
\hline & laranjas & 30 & Lab. & 19 & $<0,1$ \\
\hline \multirow[t]{2}{*}{ carbaryl } & 1 imões & 7 & Lab. & 21 & $<0,2^{C}$ \\
\hline & laranjas & 7 & Lab. & 19 & $<0,2^{C}$ \\
\hline \multirow[t]{2}{*}{ carbophenothion } & limões & 36 & Lab. & 23 & 0,02 \\
\hline & laranjas & 36 & Lab. & 21 & 0,02 \\
\hline chlordane & limões & 21 & Lab. & 9,0 & $<0,1$ \\
\hline \multirow[t]{3}{*}{ chlorfenson } & limões & 11 & Lab. & 6,4 & 0,4 \\
\hline & laranjas & 12 & Lab. & 2,3 & $<0,1$ \\
\hline & laranjas & 3 & Com. & - & 0,4 \\
\hline chlorobenzilate & limões & 36 & Lab. & 20 & $<0,2$ \\
\hline \multirow[t]{2}{*}{ DDT } & laranjas & 26 & Lab. & 10 & $<0,1$ \\
\hline & laranjas & 26 & Com. & - & $\sim 5$ \\
\hline \multirow[t]{2}{*}{ diazinon } & limões & 11 & Lab. & 12 & $<0,1$ \\
\hline & laranjas & 14 & Lab. & 4,4 & $<0,1$ \\
\hline \multirow[t]{2}{*}{ dicofol } & limões & 19 & Lab. & 16 & 0,05 \\
\hline & laranjas & 56 & Lab. & 11 & 0,15 \\
\hline dicrotophos & laranjas & 63 & Lab. & 7,2 & 0,1 \\
\hline \multirow[t]{3}{*}{ dieldrin } & limões & 5 & Lab. & 6,8 & $<0,1$ \\
\hline & laranjas & 33 & Lab. & 0,8 & $<0,1$ \\
\hline & laranjas & 6 & Com. & - & 0,1 \\
\hline dimethoa te & laranjas & 60 & Lab. & 16 & $<0,1$ \\
\hline \multirow[t]{2}{*}{ dioxathion } & limões & 40 & Lab. & 25 & 0,03 \\
\hline & laranjas & 40 & Lab. & 9,7 & 0,03 \\
\hline
\end{tabular}


Tabela 2. Continuação

\begin{tabular}{|c|c|c|c|c|c|}
\hline \multirow{2}{*}{ Inseticida } & \multirow{2}{*}{ Fruta } & \multirow{2}{*}{$\begin{array}{l}\text { Nọ de } \\
\text { amostras }\end{array}$} & \multirow{2}{*}{$\begin{array}{c}\text { Modo de } \\
\text { preparação }\end{array}$} & \multicolumn{2}{|c|}{ Resīduo māximo (ppm) } \\
\hline & & & & Casca $^{b}$ & suco ${ }^{b}$ \\
\hline \multirow[t]{2}{*}{ EPN } & laranjas & 2 & Lab. & 3,1 & $<0,1$ \\
\hline & laranjas & 9 & Com. & - & $<0,1$ \\
\hline \multirow[t]{2}{*}{ ethion } & limões & 15 & Lab. & 10 & $<0,2$ \\
\hline & laranjas & 16 & Lab. & 32 & $<0,2$ \\
\hline heptachlor & limões & 12 & Lab. & 10 & $<0,2$ \\
\hline \multirow[t]{2}{*}{ malathion } & limões & 6 & Lab. & 4,8 & 0,03 \\
\hline & laranjas & 77 & Lab. & 4,1 & 0,1 \\
\hline \multirow[t]{4}{*}{ parathion } & limões & 8 & Lab. & 3,8 & $<0,05$ \\
\hline & laranjas & 54 & Lab. & 6,0 & $<0,05$ \\
\hline & laranjas & 116 & Com. & - & $0,4^{d}$ \\
\hline & laranjas & 16 & Com. ${ }^{e}$ & - & 2,0 \\
\hline propargite & laranjas & 10 & Lab. & 9,0 & $<0,2$ \\
\hline \multirow[t]{2}{*}{ tetradifon } & limões & 27 & Lab. & 11 & $<0,03$ \\
\hline & laranjas & 21 & Lab. & 11 & $<0,03$ \\
\hline
\end{tabular}

$a-$ Lab. = laboratōrio, Com. = comercial

b - preparada no laboratório, os valores para casca e suco são das mesmas frutas, aproximadamente 30 dias após o tratamento

c - também, <0,1 ppm de $\alpha$ - naftol

d - média $0,1 \mathrm{ppm}$

e - concentrado congelado comercial

\subsubsection{Rações para gado}

Os resĩduos de pesticidas encontrados em rações para gado feitas no laboratōrio a partir de cascas e bagaço de frutas cītricas são listados na Tabela 3. 
Tabela 3. Resíduos de pesticidas em rações para gado, preparadas no laboratōrio, a partir de cascas e bagaço de frutas-citricas pro venientes de plantas que receberam tratamentos comerciais(GUN THER, 1969)

\begin{tabular}{|c|c|c|c|c|}
\hline \multirow[b]{2}{*}{ Inseticida } & \multirow[b]{2}{*}{ Fruta } & \multicolumn{3}{|c|}{ Residuos (ppm) } \\
\hline & & (no de amostras) & $\begin{array}{c}\text { ração úmida } \\
\text { (nọ de amostras) }\end{array}$ & $\begin{array}{c}\text { ração seca } \\
\text { (nọ de amostras) }\end{array}$ \\
\hline \multirow[t]{3}{*}{$\begin{array}{l}\text { azinphos } \\
\text { methyl }\end{array}$} & limões & $9,4 \pm 0,4(6)^{a}$ & $3,5 \pm 0,3(6)$ & $5,6 \pm 0,7(4):$ \\
\hline & laranjas & $4,3 \pm 0,1(3)^{a}$ & $0,7 \pm 0,1(3)$ & $1,4 \pm 0,3(3)$ \\
\hline & laranjas & $1,7^{b}$ & - & 1,5 \\
\hline carbaryl & laranjas & $15,9 \pm 2,2(6)^{a}$ & $1,6 \pm 0,2(6)$ & $2,0 \pm 0,7(5)$ \\
\hline DDT & laranjas & $3-13(6)^{c, d}$ & - & $1-10(6)$ \\
\hline \multirow[t]{3}{*}{ dicofol } & limões & $4-12(4)^{c}$ & - & $7-14(8)$ \\
\hline & laranjas & $5-9(11)^{c}$ & - & $8-17(11)$ \\
\hline & laranjas & $1,3 \pm 0,1(6)^{a}$ & $0,5 \pm 0,0(6)$ & $1,3 \pm 0,1(6)$ \\
\hline \multirow[t]{2}{*}{ dicrotophos } & laranjas & $8,6 \pm 0,6(6)^{b}$ & $7,3 \pm 0,1(6)$ & $2,4 \pm 0,2(6)$ \\
\hline & laranjas & $3,9 \pm 0,7(3)^{a}$ & - & $4,2 \pm 0,3(3)$ \\
\hline dimethoate & laranjas & $4,7 \pm 0,5(4)^{a}$ & $2,6 \pm 0,4(4)$ & $2,9 \pm 0,6(6)$ \\
\hline \multirow[t]{2}{*}{ dioxathion } & limões & $7,6 \pm 0,4(6)^{\mathrm{a}}$ & - & $41,6 \pm 2,6(4)$ \\
\hline & laranjas & $2,6 \pm 0,3(6)^{b}$ & - & $2,1 \pm 0,2(6)$ \\
\hline DN-11ו & laranjas & $1,6 \pm 0,3(10)^{\mathrm{a}}$ & $1,1 \pm 0,2(6)$ & $0,9 \pm 0,1(6)$ \\
\hline ethion & laranjas & $4,8 \pm 0,4(3)^{a}$ & - & $1,1 \pm 0,2(3)$ \\
\hline malathion & laranjas & $7,0 \pm 0,2(5)^{a}$ & $<0,2(5)$ & $<0,2(5)$ \\
\hline Morestan & laranjas & $3,8 \pm 0,2(4)^{a}$ & $1,0 \pm 0,3(6)$ & $1,0 \pm 0,2(6)$ \\
\hline \multirow[t]{2}{*}{ parathion } & limões & $1-5(6)^{c, d}$ & - & $1-6(6)$ \\
\hline & laranjas & $1-6(18)^{c, d}$ & - & $1-10(30)$ \\
\hline propargite & laranjas & $4,5 \pm 0,3(6)^{a}$ & $2,5 \pm 0,2(6)$ & $3,4 \pm 0,1(6)$ \\
\hline \multirow[t]{2}{*}{ tetradifon } & limões & $16,6 \pm 0,4(2)^{a}$ & - & $0,5 \pm 0,0(3)$ \\
\hline & laranjas & $10,7 \pm 0,2(13)^{a}$ & $0,8 \pm 0,2(10)$ & $0,8 \pm 0,3(10)$ \\
\hline
\end{tabular}

a - aproximadamente 30 dias após o tratamento

b - aproximadàmente 15 dias após o tratamento

c - apōs muitos anos, vārias datas de coletas apōs a aplicação

d - vārias datas de coletas apōs a aplicação. 
A casca toda, como extraida dos frutos normalmente possui um teor de 70 a $85 \%$ de umidade e fornece o resîduo na "casca"; a casca submetida a um tratamento com cal e prensada, com mais ou menos $40 \%$ de umidade fornece o resỉduo na "ração úmida", e o produto final tem em mëdia $7 \%$ de umidade e fornece o resīduo na "ração seca". Dessa maneira, hã um fator potencial de concentração correspondente a duas vezes de "cas ca" para "ração úmida", e um fator de concentração de quatro vezes deste estágio para produto final; dessa maneira, o fator potencial de concentração de resỉduos de cascas frescas para a ração pronta é de 8 vezes. Assim, os residuos na casca multiplicado por 8 , aproximaria o residuo máximo que pode ocorrer no produto final seco. Desde que a casca representa de $1 / 3$ a $1 / 5$ o peso da fruta fresca, multiplịcando-se o residuo da fru ta toda por 32 seria obtido uma estimativa do resỉduo máximo que poderia ser encontrado na ração feita a partir dessas frutas (GUNTHER, 1969).

Entretanto, como pode ser visto na Tabela 3 essa previsão de resĩduo total final nunca aconteceu com os inseticidas avaliados. Ao contrārio, há usualmente grandes perdas durante a preparação desse produto, durante as operações de tratamento com cal e secagem. Um exemplo extremo dessa Tabela é o malathion, que é praticamente perdido totalmente durante a operação de tratamento com cal. Dos dados apresentados, outros inseticidas que não toleram o tratamento com cal são: azinphos methyl, carbaryl e dicofol. Esse processamento destroi grande parte do DDT, ethion, propargite e parathion. Os residuos de dioxathion suportam todo o procedimento sem maiores perdas (GUNTHER, 1969). 
As informações a respeito da diminuiçăo dos nîveis de residuos pelas operações de processamento podem ser muito üteis no estabele cimento de tolerâncias eni alimentos processados e não processados, além de servirem na avaliação das possibilidades do aproveitamento de alimentos contaminados com niveis de residuos acima da tolerância, mas que podem ser reduzidos a nīveis aceitāveis pelo processamento (LISKA e STADELMAN, 1969).

\subsection{Ethion}

Ethion è um produto organofosforado, cujo nome quỉmico ē 0,0,0', $0^{\prime}$-tetraetil S,S'-metileno bisditiofosfato (Figura 4). Segundo NAKANO et alij (1977) este é um produto inseticida e acaricida que age por contato, ingestão, fumigação e profundidade. Possui valores de $\mathrm{DL}_{50}$ oral de 27 a $119 \mathrm{mg} / \mathrm{kg}$ para ratos albinos e $\mathrm{DL}_{50}$ dérmica de 62 a $245 \mathrm{mg} / \mathrm{kg} \mathrm{pa}$ ra coelhos.

0 ethion è um dos produtos recomendados para o controle de ācaros e mosca branca na citricultura na dosagem de $60 \mathrm{ml}$ de i.a. 100/1. de àgua (CAVERO et alii, 1976). Segundo NAKANO et alii (1977) quando usa do com óleo mineral pode ser utilizado também como ovicida e no controle de cochonilhas. Nesse particular, existe no mercado a formulação Ethiol 100 ( $10 \%$ de ethion mais $68 \%$ de óleo mineral) cujo emprego é recomendado pelo fabricante na dosagem de $400 \mathrm{ml}$ do produto comercial por 1001 de $\bar{a}-$ gua. 
<smiles>CCOP(=S)(OCC)SCSP(=S)(OCC)OCC</smiles>

Figura 4. Förmula plana do ethion

A tolerância e o perỉodo de carência estabelecidos pelo Grupo de Trabalho GT - 2 da Comissão Nacional de Normas e Padrões para Alimentos - C.N.N.P.A. - do Ministērio da Saūde em frutas cîtricas são 2 ppm (com base na fruta toda) e 15 dias. (GALVÃO e PIRES, s.d.).

A metodologia empregada para a anālise de resỉduos de ethion em frutas e vegetais por cromatografia a găs foi estudada por diversos pesquisadores como: NELSON (1964, 1965, 1967); STORHERR et alii (1971); LUKE et alii. (1975); VERSINO et alii. (1971); RANDALL et alii (1969).

\subsection{Fenitrothion}

Assim como o ethion, o fenitrothion é um pesticida organo fosforado, cujo nome quỉmico è 0,0-dimetil 0-(4-nitro-m-tolil) tionofosfato (Figura 5).

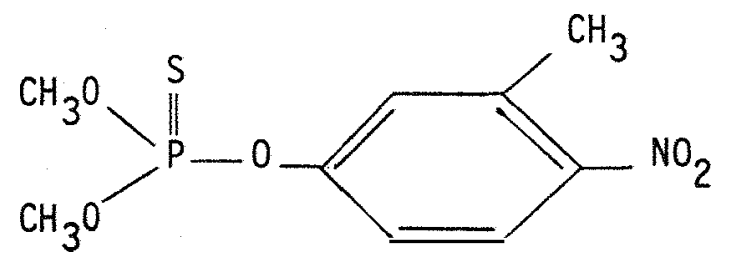

Figura 5. Förmula plana do fenitrothion 
Segundo NAKANO et ali i (1977) é um produto acaricida seletivo que age por ingestão e contato. A toxicidade expressa em valores de $\mathrm{DL}_{50} \bar{e}$ de 250 a $670 \mathrm{mg} / \mathrm{kg}$ (oral, ratos albinos) e 200 a $3000 \mathrm{mg} / \mathrm{kg}$ (dēr mica, ratos albinos).

De acordo com CAVERO et alii. (1976) para o controle de aleirodideos, cochonilhas e pulgões na citricultura o produto deve ser usado na concentração de 100-150 ml da formulação CE 50\% por 1001 de àgua. Os autores reportam ainda que este produto mostra-se eficiente no controle de ácaros.

0 Grupo de Trabalho GT-2 da C.N.N.P.A. do Ministério da Saūde estabelece o limite de tolerância de 0,4 ppm e periodo de carência de 14 dias para fenitrothion em frutas em geral (GALVAO e PIRES, s.d.).

A metodologia empregada para a anālise de resĩduos de fenitrothion em frutas e vegetais por cromatografia a gās foi estudada por LIPOWSKA et alii (1975); BOWMAN e BEROZA (1969); DAWSON et alii. (1964); MOELLHOFF (1967); STORHERR et alii (1971); RANDAL et alii (1969); SISSONS e TELLING (1970); PARDUE (1970).

3.6. Comportamento dos residuos de ethion e fenitrothion em algumas culturas

TASCHENBERG (1963) estudou o desaparecimento dos residuos de ethion e outros pesticidas em uvas. Em aplicação de 0,5 lb de i.a.l 100 gal (formulação 25\% PM), o depósito inicial foi de 8,4 ppm e 56 dias 
apōs o resīduo encontrado foi de $2 \mathrm{ppm}$. Entretanto, 0 autor verificou que o desaparecimento é influenciado pela estação do ano, pois em ensaios realizados em anos subsequentes, quatro semanas apōs a aplicação, foi encontrado $48 \%$ do depósito inicial num ano e 19\% no outro, devido ao tempo chuvoso ocorrido nesse ūltimo. As anālises dos resĩduos de ethion foram feitas por método colorimétrico com valores de recuperação de $84 \%$ a $108 \%$ em amostras fortificadas. 0 autor verificou ainda que quando as temperaturas atingiram $32^{\circ} \mathrm{C}$ ou mais altas foram encontradas rá pidas perdas nos depōsitos de ethion.

MACNEIL e HIKICHI (1976) estudaram a degradação de ethion em peras apōs a aplicação de 8 lb de Ethion-25 PM por acre. Os resíduos de ethion nas frutas atingiram 0 limite de tolerāncia ( 1 ppm), 20-35 dias apōs a aplicação. Porém, o autor constatou que da 1 a a $5^{a}$. semana houve um aumento de quatro vezes no peso das frutas. Como o decréscimo da concentração de ethion neste perĩodo foi de quatro vezes, o autor juI ga que o aparente decréscimo nos resíduos de ethion foi devido à diluição pelo aumento no tamanho do fruto. A anālise dos resĩduos foi feita com cromatōgrafo a gās equipado com detector de captura eletrōnica.

DOROUGH et alii. (1966) estudando a degradação de ethion em cultura de sorgo, verificaram que após a aplicação de 0,5 lb de i.a./ acre durante a fase de formação de grãos, os resĩduos encontrados nas foIhas foram de 4,6; 1,32 e 0,36 ppm aos 3, 6 e 14 dias apōs a aplicação.

PIGATI et alii. (1975), concluiram que o inseticida ethion quando pulverizado por cinco vezes em cafeeiros, na dosagem de 
$750 \mathrm{~g}$ i.a. $/ 1000$ plantas, acarretou 0 aparecimento de niveis de residuo da ordem de 0,03 ppm nos grãos beneficiados colhidos no estado "cereja" e de 0,04 ppm nos grãos beneficiados colhidos no estado "coco". 0 inter valo entre a ūltima aplicação e a colheita foi de 70 dias.

As anālises de resíduos de fenitrothion (Sumithion) em macieiras feitas por PATRASHKU (1971), revelaram a presença de quantida des de 0,6 a 6,0 ppm nos frutos aos 20 dias após a aplicação do produito, as quais foram consideradas como tōxicas pelo autor.

Resỉduos de 0,22 ppm de fenitrothion foram encontrados por GOLACKA (1971) em raizes de cenouras 54 dias após a pulverização das folhas. 0 resĩduo em folhas de alface foi de $0,22 \mathrm{ppm}$ aos 21 dias após a aplicação.

Estudos sobre os residuos de fenitrothion (Folithion EC50) em plantas de repolho foram desenvolvidos por ZWOLINSKA-SNIATOWA e TROJANOWSKI (1971) usando cromatografia a gās. 0 produto foi aplicado em pulverização nas concentrações de 0,1 e $0,3 \%$ do produto comercial. Quatro dias apōs a aplicação, as plantas mostraram-se com baixas quantidades de fenitrothion $(0,15$ e 0,6 ppm para a menor e a maior dosagem, respectivamente). Estes nīveis caīram para 0,03 e 0,1 ppm 21 dias após a aplicação. 


\section{MATERIAIS E METODOS}

\subsection{Instalação do experimento}

0 presente experimento foi instalado em pomar de laranjas da variedade Mamlin, de sete anos de idade, localizado no município de Cordeirōpolis, S.P., na Estação Experimental de Citricultura do Instituto Agronômico de Campinas.

Os produtos utilizados e suas respectivas dosagens foram: $400 \mathrm{ml}$ de Ethiol 100 (40 ml de i.a.) e $150 \mathrm{ml}$ de Folithion 50 CE (75 ml de i.a.) por 100 litros de āgua.

0 produto comercial Ethiol 100 apresenta 10\% de ethion mais $68 \%$ de óleo mineral.

A aplicação dos produtos foi realizada em 6 de março de 1979, ocasião em que os frutos da variedade de laranja em referéncia es tavam em fase inicial de maturação. O tamanho das ärvores utilizadas e o estāgio de maturação dos frutos, 45 dias apōs a aplicação, são mostrados na Figura 6. 


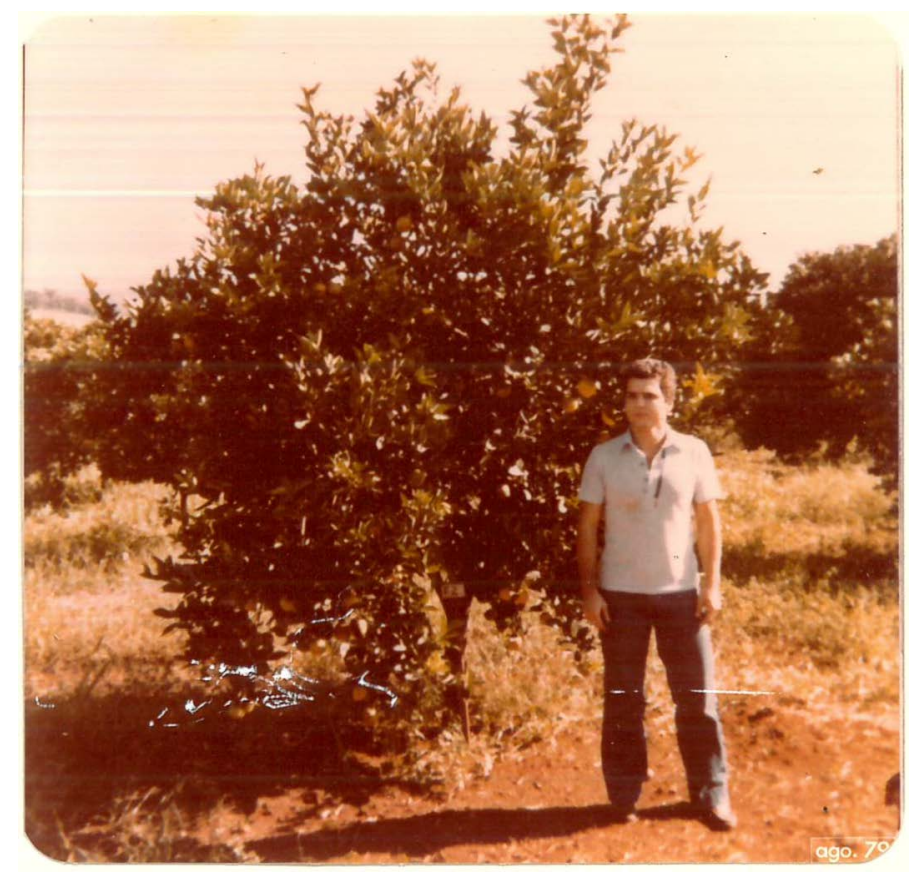

Figura 6. Foto mostrando o tamanho das ārvores de laranja utilizadas no presente trabalho, assim como o estāgio de maturação dos frutos 45 dias apōs a aplicação

Utilizou-se um pulverizador costal motorizado marca Hatsu ta e procurou-se molhar cada planta uniformemente até o inỉcio de escorrimento, para o que foram gastos em média 1,7 litros de calda por planta, correspondendo a $1,275 \mathrm{ml}$ i.a. de fenitrothion e 0,680 ml i.a. de ethion por planta. Na preparação da calda utilizou-se o espalhante adesivo Extravon 200 na quantidade de $20 \mathrm{ml} / 100$ litros de agua. Para cada tratamento (produto) observou-se um total de três repetições e cada plan ta foi considerada como uma repetição.

Os frutos foram amostrados aos $3,10,17,24,34,45,60$ e 104 dias apos a aplicação, sendo esta sequência basicamente aquela utị lizada por IWATA et alii (1977). 
$\mathrm{Na}$ operação de amostragem, de cada planta foram coletados 16 frutos ao acaso, os quais foram acondicionados em sacos de papel. No laboratōrio as cascas foram separadas das polpas com auxîlio de um descascador de aluminio (GUNTHER, 1969).

Com auxîlio de um vazador de metal de $2 \mathrm{~cm}$ de diāmetro e $12 \mathrm{~cm}$ de comprimento, foi retirado um cilindro da polpa de cada laranja.

As cascas foram moidas em moedor marca Lico e o material obtido foi homogeneizado. Em seguida, procedeu-se à pesagem de $100 \mathrm{~g}$ de polpas e de cascas, em duplicata. As amostras foram, então, acondicionadas em sacos de polietileno e mantidas em congelador a $-20^{\circ} \mathrm{C}$, até $\quad 0$ momento de serem analizadas.

A preparação das amostras dessa maneira, seguiu basicamen te àquela proposta por GUNTHER (1969); apenas o número de frutos por planta em cada amostragem foi reduzido à metade daquele proposto pelo autor, pois a quantidade de frutos nas ārvores utilizadas no presente experimento era relativamente baixa.

4.2. Limites de detecção, porcentagens de recuperação e descrição do método de anālise de residuos.

A fim de se estabelecer o limite de detecção e a porcentagem de recuperação de ethion e fenitrothion em cascas e polpas de laranjas Hamlin pelo método analitico empregado, amostras de $100 \mathrm{~g}$ prepara das de maneira idêntica àquelas provenientes de plantas tratadas, foram fortificadas de maneira a se obter concentrações de 0,$5 ; 0,1 ; 0,05 ; 0,02$ 
e 0,01 ppm para cascas e 0,05; 0,02 e 0,01 ppm para polpas. Também nesse caso as determinações foram feitas em duplicata.

0 método de anālise de resíduos foi adaptado daquele desenvolvido por MÖLLHOFF (1967). As amostras (cascas e polpas) são submetidas à extração com acetona; em seguida é feita partição em clorofōrmio. A limpeza do extrato é efetuada em coluna de florisil, sendo a eluição procedida com benzeno. Segue-se a determinação quantitativa feita em cromatógrafo equipado com detector de ionização de chama alcalina (DICA).

\subsubsection{Reagentes}

acetona - PA - ACS destilada em destilador de vidro;

clorofórmio - PA - ACS destilado em destilador de vidro;

benzeno - PA - ACS destilado em destilador de vidro;

florisil - 60 - 100 mesh, mantido em estufa a $140^{\circ} \mathrm{C}$, e no dia anterior ao da anālise desativado com $5 \%$ de água destilada;

$\mathrm{Na}_{2} \mathrm{SO}_{4}$ - anidro, granulado;

padrões analiticos de ethion e fenitrothion.

4.2.2. Aparelhos, vidraria e outros materiais cromatógrafo CG - modelo 3700 , equipado com detector de ionização de chama alcalina (DICA); 
coluna cromatogrāfica - vidro, diāmetro de 1/8", com comprimento de $1,8 \mathrm{~m}$ e empacotada com 10\% DC 200/chromosorb W silanizado; evaporador rotativo a vācuo - marca Büchi; liquidificador - marca Waring Blendor; bomba pneumātica - marca G.E. (1/4 HP); microseringa $(10 \mu 1)$ - marca Hamilton; coluna cromatogräfica - vidro, $20 \times 300 \mathrm{~mm}$, porosidade grosseira, provida com torneira de Teflon;

frascos redondos - $500 \mathrm{ml}$;

funil de Buchner - 100 mm de diāmetro;

funil de separação - $500 \mathrm{ml}$;

quitassato - $500 \mathrm{ml}$ de capacidade;

provetas graduadas - 100 e $250 \mathrm{ml}$;

pipetas - 1,2,5, e $10 \mathrm{ml}$;

tubos de centrifuga graduados; papel de filtro - Whatman no 5.

\subsubsection{Marcha analitica}

\section{A - Extração}

A.1 - Transferir a amostra de $100 \mathrm{~g}$ (cascas ou polpas) pa ra o copo do liquidificador, juntar $150 \mathrm{ml}$ de acetona e homogeneizar por 3 minutos. 
A.2 - filtrar em funil de Buchner atravēs de papel de fil tro para o quitassato, com auxỉlio de vācuo fornecido pela bomba pneumática.

A.3 - no caso de anālise de polpa, tomar uma alíquota de $115 \mathrm{ml}$ em proveta graduada e transferi-la para o funil de separação. No caso de anālise de cascas, lavar os conteūdos do funil de Buchner com $50 \mathrm{ml}$ de acetona; tomar uma alíquota igual à metade do volume obtido no quitassato e transferī-la para o funil de separação.

A.4 - juntar ao funil $100 \mathrm{ml}$ de clorofórmio; agitar vigorosamente por 30 segundos e esperar a separação das fases. Drenar a camada inferior para um frasco redondo, filtrando atravēs de $50 \mathrm{~g}$ de $\mathrm{Na}_{2} \mathrm{SO}_{4}$ suspenso num funil de vidro.

A.5 - repetir a operação com mais $100 \mathrm{ml}$ de clorofórmio.

A.6 - evaporar um evaporador rotativo a vācuo em banhomaria a $60^{\circ} \mathrm{C}$, até mais ou menos $2-5 \mathrm{ml}$; evaporar o solvente remanescente com auxîlio de vācuo.

\section{B - Limpeza do extrato}

B. 1 - preparar coluna cromatogräfica de $20 \times 300 \mathrm{~mm}$ provida de torneira de Teflon. Com a torneira fechada adicionar benzeno su ficiente para alcançar $10 \mathrm{~cm}$ de altura na coluna; juntar $8 \mathrm{~g}$ de florisil, que tïnha sido desativado com 5\% de àgua destilada no dia anterior, sendo este cuidadosamente colocado pelo topo da coluna; com auxîlio de um vibrador (régua de madeira) eliminar bolhas de ar que por acaso ocorram na camada de florisil; drenar o benzeno até o nível do florisil. 
B.2 - dissolver os residuos provenientes de $A .6$ em $10 \mathrm{ml}$ de benzeno e introduzir na coluna.

B.3 - eluir a coluna com $100 \mathrm{ml}$ de benzeno medido em proveta, usando duas porções iniciais de $10 \mathrm{ml}$ para lavar o frasco redondo, introduzindo cada uma apōs a completa penetração da anterior no florisil. Apōs a penetração da segunda porção, colocar os $80 \mathrm{ml}$ restantes dí retamente na coluna, recolhendo todo o eluado em frasco redondo 1 impo. Regular a abertura da torneira de modo a se conseguir uma eluição com ve locidade de 80 a 100 gotas por minutos.

B.4 - evaporar em evaporador rotativo a vācuo em banhomaria a $60^{\circ} \mathrm{C}$, até mais ou menos $2-5 \mathrm{ml}$; evaporar o solvente remanescente com auxîlio de vácuo.

\section{C - Determinação quanti.tativa}

C.1 - diluir os resîduos provenientes de B.4, lavando 0 frasco redondo com exatamente $5 \mathrm{ml}$ de acetona e recolher a lavagem em tubo de centrífuga graduado.

C.2 - injetar alíquotas no cromatōgrafo.
C.3 - condições de operação do cromatōgrafo:
Coluna - vidro; $\varnothing=1 / 8^{\prime \prime}$; comprimento: $1,8 \mathrm{~m}$; fase liquida: DC 200 - 10\%; suporte: chromosorb W silanizado;

temperatura da coluna $-230^{\circ} \mathrm{C}$;

temperatura do detector $-260^{\circ} \mathrm{C}$;

temperatura do vaporizador $-240^{\circ} \mathrm{C}$; 
fluxos dos gases: $\mathrm{N}_{2}=30 \mathrm{ml} / \mathrm{min}$.

$$
\begin{aligned}
& \text { ar }=210 \mathrm{ml} / \mathrm{min} . \\
& H_{2}=40 \mathrm{ml} / \mathrm{min} .
\end{aligned}
$$

C.4 - Cálculo dos resîduos:

$$
\text { Resĩduos em ppm }=\frac{\mathrm{mp} \times \mathrm{ha}}{10 \times \mathrm{hp} \times \mathrm{vi}}
$$

onde :

$$
\begin{aligned}
\mathrm{mp}= & \text { massa injetada do padrão em } \mathrm{ng} ; \\
\mathrm{ha}= & \text { altura ou ārea do pico da substância na amostra } \\
& \left(\mathrm{mm} \text { ou } \mathrm{mm}^{2}\right) ; \\
\mathrm{hp} \mathrm{=} & \text { altura ou ārea do pico da substância no padrão } \\
& \left(\mathrm{mm} \text { ou } \mathrm{mm}^{2}\right) ; \\
v i= & \text { volume da injeção da amostra em } \mu \mathrm{l} .
\end{aligned}
$$

Para quantificação dos resĩduos foi adotada a sugestão de THOMPSON (1977) segundo a qual picos de eluição mais cedo devem ser quan tificados pelo método da altura e picos de eluição tardia o são pelo método da altura vezes a base tomada na metade da altura. De acordo com essa proposição o fenitrothion foi quantificado pelo primeiro método e o ethion pelo ültimo. 
5. RESULTADOS E DISCUSSAO

5.1. Limites de detecção e porcentagens de recuperação do método

Os resultados obtidos de porcentagens de recuperação em amostras de cascas e polpas fortificadas são mostrados na Tabela 4.

Tabela 4. Porcentagens de recuperação de ethion e fenitrothion pelo mētodo de MÖLLHOFF (1967) de cascas e polpas de laranja fortifi cadas

\begin{tabular}{|c|c|c|c|c|c|}
\hline \multirow{2}{*}{ Casca } & \multicolumn{5}{|c|}{ Niveis de fortificação (ppm) } \\
\hline & 0,5 & 0,1 & 0,05 & 0,02 & 0,01 \\
\hline fenitrothion & $\begin{array}{l}92 \\
93\end{array}$ & $\begin{array}{l}94 \\
96\end{array}$ & $\begin{array}{l}95 \\
93\end{array}$ & $\begin{array}{l}<L . D . \\
<L . D .\end{array}$ & $\begin{array}{l}<L . D . \\
<L . D .\end{array}$ \\
\hline ethion & $\begin{array}{r}97 \\
103 \\
\end{array}$ & $\begin{array}{l}96 \\
94 \\
\end{array}$ & $\begin{array}{r}100 \\
95 \\
\end{array}$ & $\begin{array}{r}100 \\
95 \\
\end{array}$ & $\begin{array}{l}102 \\
101 \\
\end{array}$ \\
\hline \multicolumn{6}{|l|}{ Polpa } \\
\hline fenitrothion & - & - & $\begin{array}{l}102 \\
100\end{array}$ & $\begin{array}{l}82 \\
86\end{array}$ & $\begin{array}{l}<L . D . \\
<L . D .\end{array}$ \\
\hline ethion & - & - & $\begin{array}{l}92 \\
98\end{array}$ & $\begin{array}{r}104 \\
97\end{array}$ & $\begin{array}{r}97 \\
102\end{array}$ \\
\hline
\end{tabular}


Como pode ser observado pelos resultados obtidos, em todos os niveis de fortificação efetuados de ethion em cascas e polpas, hou ve uma porcentagem de recuperação superior a $92 \%$. Uma vez que, no nīvel de $0,01 \mathrm{ppm}$ a massa teōrica do produto injetada no cromatōgrafo seria de $4 \mathrm{ng}$ (injeção de $8 \mu \mathrm{l}$ da amostra proveniente de 4.2.3.-C.1, concentrada 5 vezes), a qual se aproxima do limite de detecção do aparelho nas condições anteriormente citadas, ficou estabelecido o limite de deteç̧ão (L.D.) de 0,01 ppm para ethion em cascas e polpas.

As anālises das fortificações efetuadas com fenitrothion em cascas, revelaram porcentagens de recuperação bastante satisfatōrias em concentrações acima de 0,05ppm, porēm, em concentrações abaixo desta, a quantificação dos picos obtidos no cromatograma tornou-se dificultada pela presença de impurezas interferentes nas condições da anaTise cromatogrāfica efetuada. Nas anālises de polpas não houve esse tipo de problema, e o limite de deteç̧ão nesse caso ficou restrito à sensibilidade do apare tho ao referido produto. Assim, ficaram estabelecidos os limites de deteç̧ão de 0,05 e $0,02 \mathrm{ppm}$ de fenitrothion para cascas e polpas, respectivamente.

Portanto, o método de MöLLLHOFF (1967) originalmente recomendado para anālise de resíduos de pesticidas organofosforados em couve, alface, batata, cebola, maçãs e amostras de solo, mostrou ser viável também para a anālise de resíduos de ethion e fenitrothion em cascas e polpas de laranjas. 
Os cromatogramas obtidos nas fortificações de ethion $(0,01 \mathrm{ppm}$ em cascas e 0,05 ppm em polpas) e 0,05 ppm de fenitrothion em amostras de cascas e polpas são mostrados nas Figuras 7, 8, 9 e 10. 


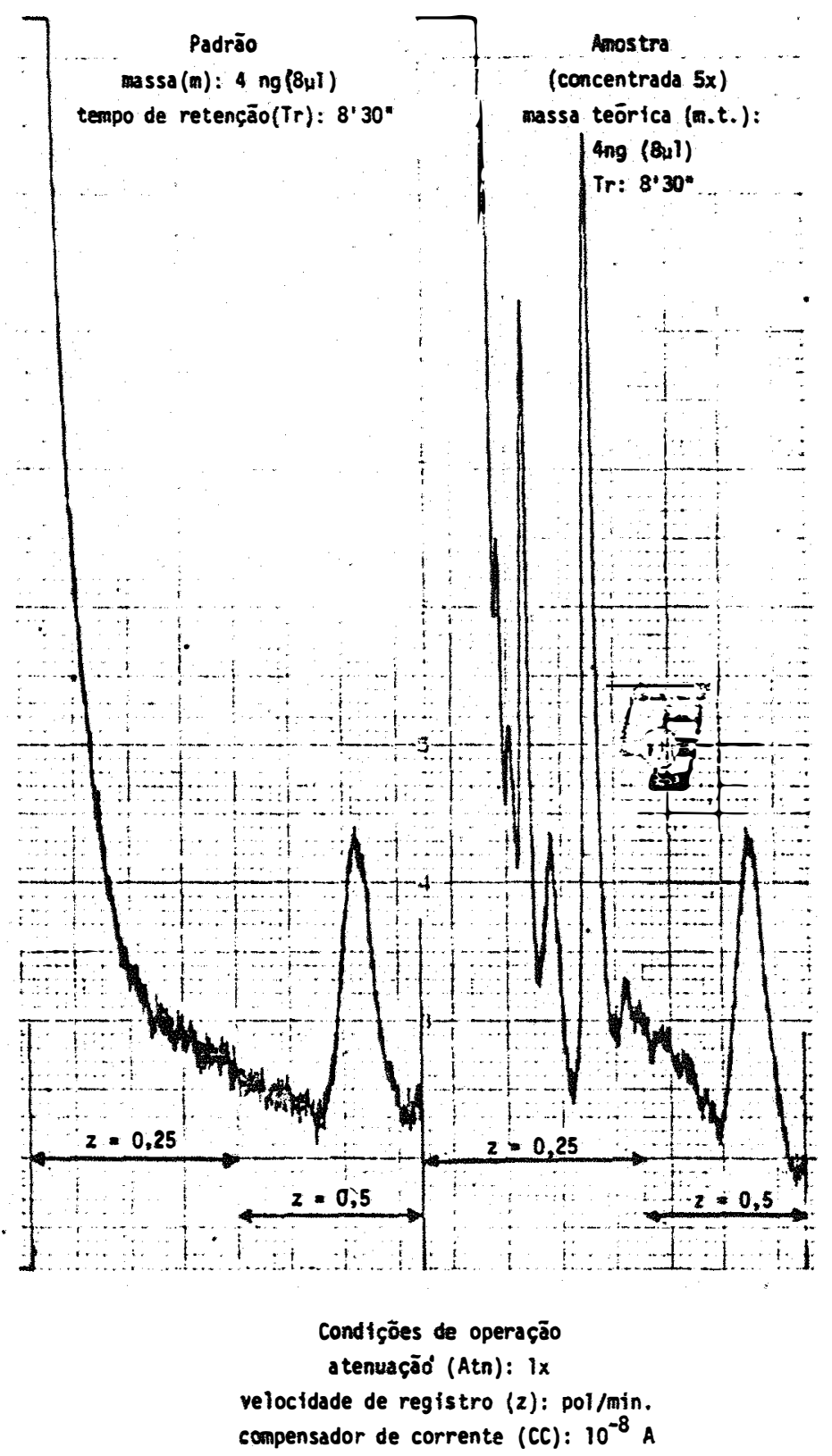

Figura 7. Cromatogramas da fortificação de $0,01 \mathrm{ppm}$ de ethion em cascas 


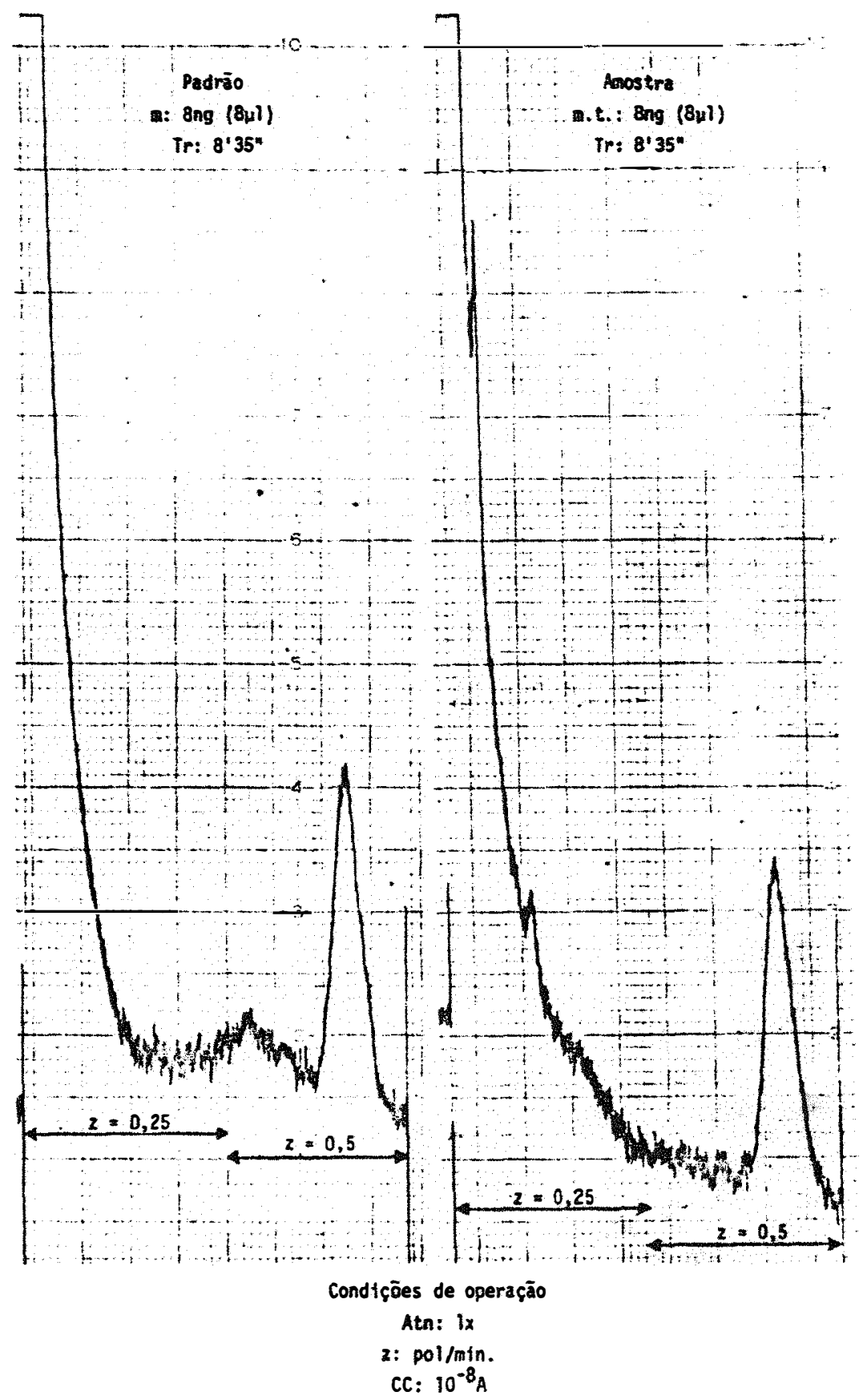

Figura 8. Cromatogramas da fortificação de $0,05 \mathrm{ppm}$ de ethion em polpas 


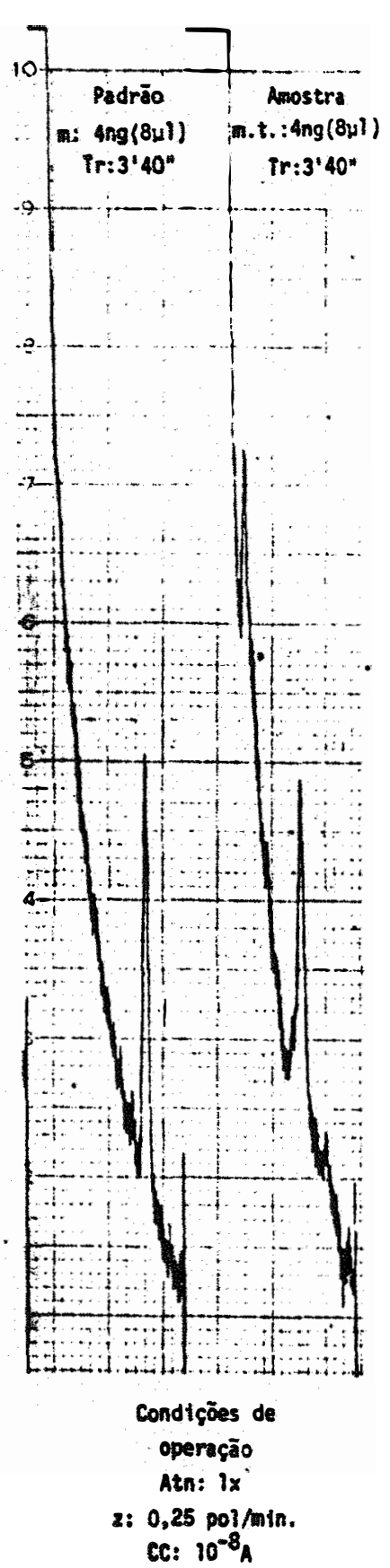

Figura 9. Cromatogramas da fortificação de 0,05 ppm de fenitrothion em cascas

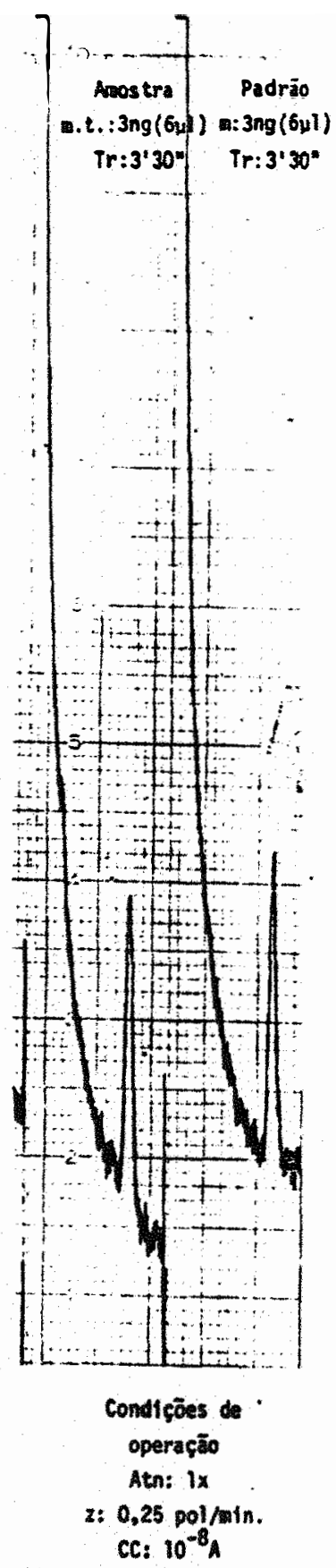

Figura 10. Cromatogramas da fortificação de 0,05 ppm de fenitrothion em pol pas 
5.2. Residuos de ethion e fenitrothion nas cascas e polpas dos frutos

Os resultados obtidos nas anālises de frutos provenientes de plantas tratadas no campo são apresentados nas Tabelas 5 e 6 e nas Figuras 11 e 12.

Da observação das Tabelas 5 e 6 , verifica-se que os $n \overline{7}-$ veis de residuos de ethion nas cascas dos frutos foram prōximos ao dobro daqueles de fenitrothion atē 45 dias apōs a aplicação, porém, posteriormente a esta data de amostragem, os residuos de ethion desapareceram mais rapidamente que aqueles de fenitrothion. Apesar da quantidade de ingrediente ativo por planta ter sido menor para ethion $(0,68 \mathrm{ml})$ do que para fenitrothion $(1,275 \mathrm{ml}), j \bar{a}$ aos 3 dias apōs a aplicação os resíduos de ethion encontrados foram praticamente o dobro daqueles de fenitrothion, indicando uma perda no depósito inicial mais rāpida deste ültimo. Provavelmente, isso tenha sido devido ao óleo mineral contido na formulação Ethiol 100, que deve exercer papel importante na retenção do ingrediente ativo sobre a superfície dos frutos.

Como pode ser observado, não houve detecção de resĩduos na parte comestivel das frutas em quaisquer dos dias apōs a aplicação, indicando nenhuma ou talvez muito pouca (não detectável) penetração dos residuos na polpa, e que a casca funciona como grande barreira contra a penetração dos resĩduos. 
Tabela 5. Resĩduos de ethion, expressos em ppm, na casca e na polpa de frutos de laranja provenientes de plantas pulverizadas com $400 \mathrm{ml}$ de Ethiol 100 ( $10 \%$ de ethion mais $68 \%$ de ōleo mineral $)^{a}$ por 100 litros de àgua

\begin{tabular}{|c|c|c|c|c|c|}
\hline \multirow{2}{*}{\multicolumn{2}{|c|}{$\begin{array}{l}\text { Dias apōs } \\
\text { a } \\
\text { aplicação }\end{array}$}} & \multicolumn{3}{|c|}{ Repetições } & \multirow[t]{2}{*}{ Média } \\
\hline & & A & B & $C$ & \\
\hline \multirow[t]{2}{*}{3} & casca & $\begin{array}{l}4,55 \\
4,50\end{array}$ & $\begin{array}{l}4,62 \\
4,85\end{array}$ & $\begin{array}{l}4,55 \\
4,80\end{array}$ & $4,64 \pm 0,15$ \\
\hline & polpa & $\begin{array}{l}n \cdot d \cdot b \\
n \cdot d .\end{array}$ & $\begin{array}{l}\text { n.d. } \\
\text { n.d. }\end{array}$ & $\begin{array}{l}\text { n.d. } \\
\text { n.d. }\end{array}$ & \\
\hline \multirow[t]{2}{*}{10} & casca & $\begin{array}{l}2,13 \\
2,43\end{array}$ & $\begin{array}{l}2,14 \\
2,12\end{array}$ & $\begin{array}{l}2,34 \\
2,34\end{array}$ & $2,25 \pm 0,14$ \\
\hline & polpa & $\begin{array}{l}\text { n.d. } \\
n \cdot d .\end{array}$ & $\begin{array}{l}\text { n.d. } \\
n \cdot d .\end{array}$ & $\begin{array}{l}\text { n.d. } \\
\text { n.d. }\end{array}$ & \\
\hline \multirow[t]{2}{*}{17} & casca & $\begin{array}{l}2,00 \\
2,04\end{array}$ & $\begin{array}{l}2,32 \\
2,45\end{array}$ & $\begin{array}{l}2,18 \\
2,10\end{array}$ & $2,18 \pm 0,17$ \\
\hline & polpa & $\begin{array}{l}\text { n.d. } \\
\text { n.d. }\end{array}$ & $\begin{array}{l}\text { n.d. } \\
\text { n.d. }\end{array}$ & $\begin{array}{l}\text { n.d. } \\
\text { n.d. }\end{array}$ & \\
\hline \multirow[t]{2}{*}{24} & casca & $\begin{array}{l}1,76 \\
1,66\end{array}$ & $\begin{array}{l}1,68 \\
1,76\end{array}$ & $\begin{array}{l}1,91 \\
1,92\end{array}$ & $1,78 \pm 0,11$ \\
\hline & polpa & $\begin{array}{l}\text { n.d. } \\
\text { n.d. }\end{array}$ & $\begin{array}{l}\text { n.d. } \\
\text { n.d. }\end{array}$ & $\begin{array}{l}\text { n.d. } \\
\text { n.d. }\end{array}$ & \\
\hline \multirow[t]{2}{*}{34} & casca & $\begin{array}{l}1,40 \\
1,36\end{array}$ & $\begin{array}{l}1,46 \\
1,33\end{array}$ & $\begin{array}{l}1,46 \\
1,54\end{array}$ & $1,42 \pm 0,08$ \\
\hline & polpa & $\begin{array}{l}\text { n.d. } \\
\text { n.d. }\end{array}$ & $\begin{array}{l}\text { n.d. } \\
\text { n.d. }\end{array}$ & $\begin{array}{l}\text { n.d. } \\
\text { n.d. }\end{array}$ & \\
\hline
\end{tabular}


Tabela 5. Continuação

\begin{tabular}{|c|c|c|c|c|c|}
\hline \multirow{2}{*}{$\begin{array}{c}\text { Dias apōs } \\
\text { a } \\
\text { aplicação }\end{array}$} & & \multicolumn{3}{|c|}{ Repetiçöes } & \multirow{2}{*}{ Média } \\
\hline & & $A$ & B & C & \\
\hline \multirow[t]{2}{*}{45} & casca & $\begin{array}{l}1,27 \\
1,28\end{array}$ & $\begin{array}{l}1,66 \\
1,69\end{array}$ & $\begin{array}{l}1,37 \\
1,18\end{array}$ & $1,41 \pm 0,21$ \\
\hline & polpa & $\begin{array}{l}\text { n.d. } \\
\text { n.d. }\end{array}$ & $\begin{array}{l}\text { n.d. } \\
\text { n.d. }\end{array}$ & $\begin{array}{l}\text { n.d. } \\
\text { n.d. }\end{array}$ & \\
\hline \multirow[t]{2}{*}{60} & casca & $\begin{array}{l}0,82 \\
0,89\end{array}$ & $\begin{array}{l}0,84 \\
0,92\end{array}$ & $\begin{array}{l}0,91 \\
0,92\end{array}$ & $0,88 \pm 0,04$ \\
\hline & polpa & $\begin{array}{l}\text { n.d. } \\
\text { n.d. }\end{array}$ & $\begin{array}{l}\text { n.d. } \\
\text { n.d. }\end{array}$ & $\begin{array}{l}\text { n.d. } \\
\text { n.d. }\end{array}$ & \\
\hline \multirow[t]{2}{*}{104} & casca & $\begin{array}{l}0,68 \\
0,68\end{array}$ & $\begin{array}{l}0,47 \\
0,48\end{array}$ & $\begin{array}{l}0,56 \\
0,55\end{array}$ & $0,57 \pm 0,09$ \\
\hline & polpa & $\begin{array}{l}\text { n.d. } \\
\text { n.d. }\end{array}$ & $\begin{array}{l}\text { n.d. } \\
\text { n.d. }\end{array}$ & $\begin{array}{l}\text { n.d. } \\
\text { n.d. }\end{array}$ & \\
\hline
\end{tabular}

a porcentagem de ethion confirmada por anālise cromatogrāfica

$b_{\text {n.d. }}$ não detectāvel $(<0,01$ ppm $)$ 
Tabela 6. Residuos de fenitrothion, expressos em ppm, na casca e na pol pa de frutos de laranja provenientes de plantas pulverizadas com $150 \mathrm{ml}$ de Folithion 50 C.E. ${ }^{a}$ por 100 litros de āgua

\begin{tabular}{|c|c|c|c|c|c|}
\hline \multirow{2}{*}{$\begin{array}{c}\text { Dias apōs } \\
\text { a } \\
\text { aplicação }\end{array}$} & & \multicolumn{3}{|c|}{ Repetições } & \multirow{2}{*}{ Média } \\
\hline & & A & B & c & \\
\hline \multirow[t]{2}{*}{3} & casca & $\begin{array}{l}1,98 \\
2,07\end{array}$ & $\begin{array}{l}2,13 \\
2,11\end{array}$ & $\begin{array}{l}2,01 \\
2,02\end{array}$ & $2,05 \pm 0,06$ \\
\hline & polpa & $\begin{array}{l}\text { n.d. } \\
\text { n.d. }\end{array}$ & $\begin{array}{l}\text { n.d. } \\
\text { n.d. }\end{array}$ & $\begin{array}{l}\text { n.d. } \\
\text { n.d. }\end{array}$ & \\
\hline \multirow[t]{2}{*}{10} & casca & $\begin{array}{l}1,10 \\
1,07\end{array}$ & $\begin{array}{l}1,06 \\
1,07\end{array}$ & $\begin{array}{l}1,24 \\
1,18\end{array}$ & $1,12 \pm 0,07$ \\
\hline & polpa & $\begin{array}{l}\text { n.d. } \\
\text { n.d. }\end{array}$ & $\begin{array}{l}\text { n.d. } \\
\text { n.d. }\end{array}$ & $\begin{array}{l}\text { n.d. } \\
\text { n.d. }\end{array}$ & \\
\hline \multirow[t]{2}{*}{17} & casca & $\begin{array}{l}0,90 \\
0,93\end{array}$ & $\begin{array}{l}0,82 \\
0,87\end{array}$ & $\begin{array}{l}1,16 \\
1,08\end{array}$ & $0,96 \pm 0,13$ \\
\hline & polpa & $\begin{array}{l}\text { n.d. } \\
\text { n.d. }\end{array}$ & $\begin{array}{l}\text { n.d. } \\
\text { n.d. }\end{array}$ & $\begin{array}{l}\text { n.d. } \\
\text { n.d. }\end{array}$ & \\
\hline \multirow[t]{2}{*}{24} & casca & $\begin{array}{l}0,84 \\
0,80\end{array}$ & $\begin{array}{l}0,97 \\
0,93\end{array}$ & $\begin{array}{l}0,72 \\
0,75\end{array}$ & $0,83 \pm 0,10$ \\
\hline & polpa & $\begin{array}{l}\text { n.d. } \\
\text { n.d. }\end{array}$ & $\begin{array}{l}\text { n.d. } \\
\text { n.d. }\end{array}$ & $\begin{array}{l}\text { n.d. } \\
\text { n.d. }\end{array}$ & \\
\hline \multirow[t]{2}{*}{34} & casca & $\begin{array}{l}0,82 \\
0,86\end{array}$ & $\begin{array}{l}0,63 \\
0,57\end{array}$ & $\begin{array}{l}0,75 \\
0,74\end{array}$ & $0,73 \div 0,11$ \\
\hline & polpa & $\begin{array}{l}\text { n.d. } \\
\text { n.d. }\end{array}$ & $\begin{array}{l}\text { n.d. } \\
\text { n.d. }\end{array}$ & $\begin{array}{l}\text { n.d. } \\
\text { n.d. }\end{array}$ & \\
\hline
\end{tabular}


Tabela 6. Continuação

\begin{tabular}{|c|c|c|c|c|c|}
\hline \multirow{2}{*}{$\begin{array}{c}\text { Dias apōs } \\
\text { a } \\
\text { aplicação }\end{array}$} & & \multicolumn{3}{|c|}{ Repetições } & \multirow{2}{*}{ Média } \\
\hline & & A & $B$ & C & \\
\hline \multirow[t]{2}{*}{45} & casca & $\begin{array}{l}0,80 \\
0,76\end{array}$ & $\begin{array}{l}0,78 \\
0,72\end{array}$ & $\begin{array}{l}0,64 \\
0,76\end{array}$ & $0,74 \pm 0,06$ \\
\hline & polpa & $\begin{array}{l}\text { n.d. } \\
\text { n.d. }\end{array}$ & $\begin{array}{l}n \cdot d . \\
n \cdot d .\end{array}$ & $\begin{array}{l}\text { n.d. } \\
\text { n.d. }\end{array}$ & \\
\hline \multirow[t]{2}{*}{60} & casca & $\begin{array}{l}0,72 \\
0,73\end{array}$ & $\begin{array}{l}0,51 \\
0,51\end{array}$ & $\begin{array}{l}0,60 \\
0,59\end{array}$ & $0,61 \pm 0,10$ \\
\hline & polpa & $\begin{array}{l}\text { n.d. } \\
\text { n.d. }\end{array}$ & $\begin{array}{l}\text { n.d. } \\
\text { n.d. }\end{array}$ & $\begin{array}{l}n \cdot d . \\
n \cdot d .\end{array}$ & \\
\hline \multirow[t]{2}{*}{104} & casca & $\begin{array}{l}0,51 \\
0,47\end{array}$ & $\begin{array}{l}0,44 \\
0,45\end{array}$ & $\begin{array}{l}0,42 \\
0,42\end{array}$ & $0,45 \pm 0,03$ \\
\hline & polpa & $\begin{array}{l}\text { n.d. } \\
\text { n.d. }\end{array}$ & $\begin{array}{l}\text { n.d. } \\
\text { n.d. }\end{array}$ & $\begin{array}{l}\text { n.d. } \\
\text { n.d. }\end{array}$ & \\
\hline
\end{tabular}

a porcentagem de fenitrothion na formulação confirmada por anālise cromatogrāfica

$b_{\text {n.d. }}=$ não detectāvel $(<0,02 \mathrm{ppm})$ 


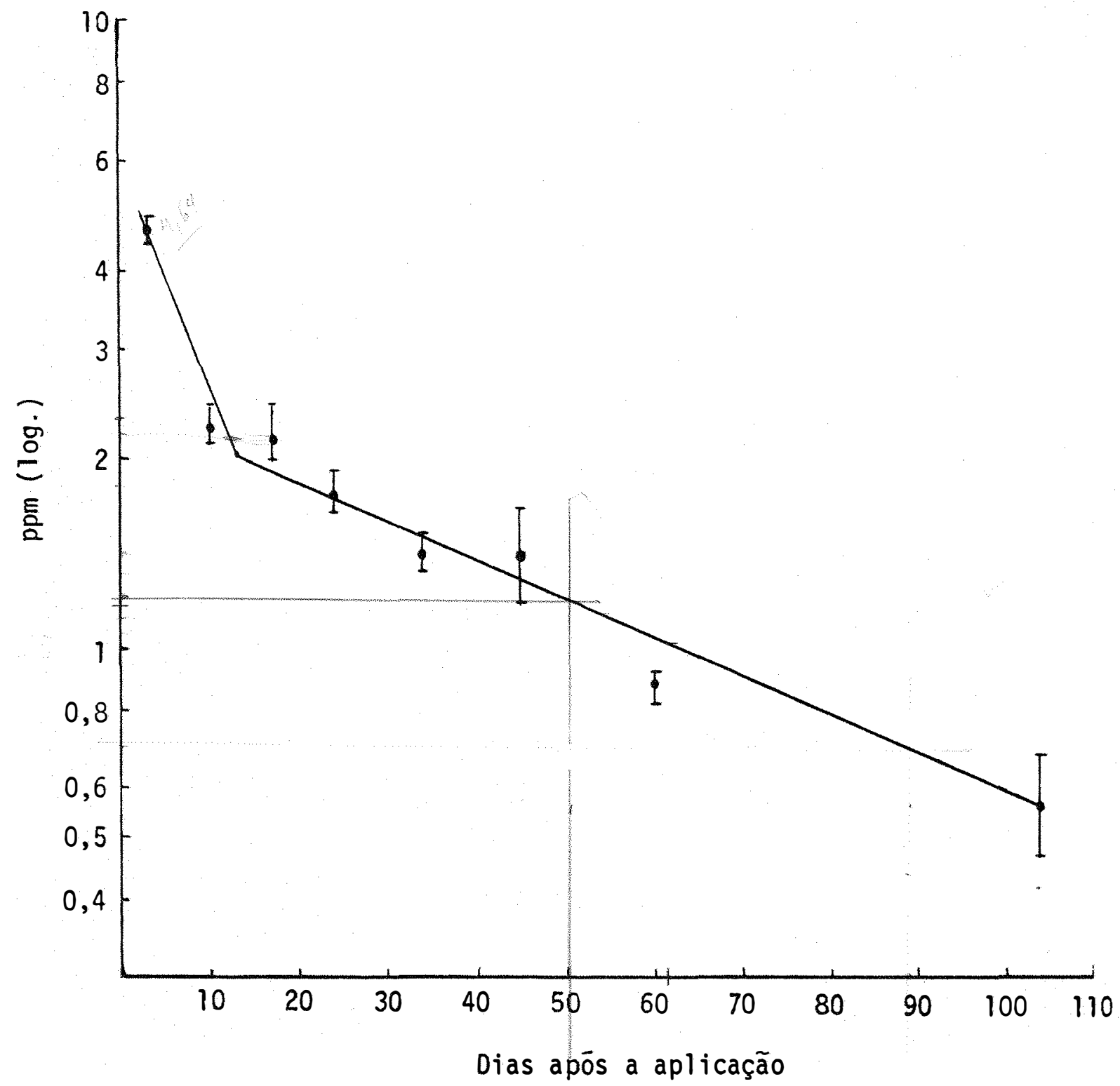

Figura 11. Curvas de degradação e persistência de resîduos de ethion so bre e no interior de cascas de laranjas Hamlin provenientes de plantas pulverizadas com $400 \mathrm{ml}$ de Ethiol 100 por $100 \mathrm{li}$ tros de āgua 


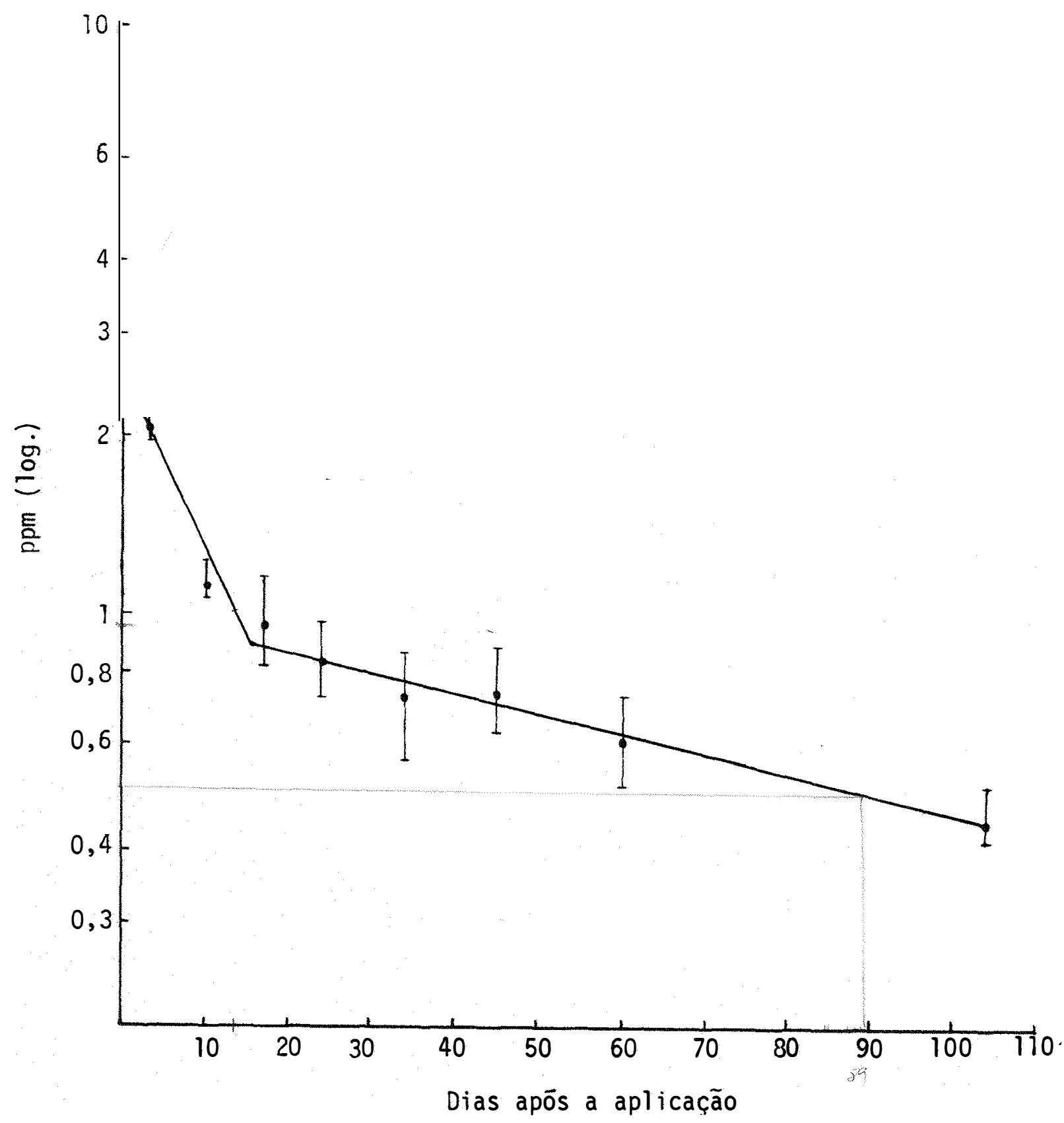

Figura 12. Curvas de degradação e persistência de resỉduos de fenitrothion sobre e no interior de cascas de laranjas Haml in provenientes de plantas pulverizadas com $150 \mathrm{ml}$ de Folithion 50 CE por 100 litros de àgua 
As figuras 11 e 12 mostram as curvas de degradação e persistência de ethion e fenitrothion sobre e no interior das cascas de la ranjas Hamlin.

Observa-se para ambos os pesticidas uma diminuição dos re siduos de maneira mais acentuada na fase inicial do experimento (curva de degradação), o que estā em concordância com resultados obtidos por ou tros autores em estudos sobre o comportamento de residuos de pesticidas organofosforados em frutras citricas (BLINN et alii, 1959; GUNTHER et alii, 1962; IWATA et alii, 1977).

Com base nas Figuras 11 e 12, os valores determinados de meia-vida de persistência foram 50 e 89 dias, respectivamente para ethion e fenitrothion, mostrando ser este ūltimo mais persistente que o primeiro em cascas de laranjas Hamlin. Os valores de meia-vida de persistência para ethion em cascas de laranjas Valência encontrados pór GUNTHER (1962) foram de 42 dias (120 g de Ethion PM 25\% por 1001 ) e 25 dias $(62,5 \mathrm{ml}$ de Ethion CE $87 \%+1,751$ de ōleo mineral/100 1). Assim, o valor de meia-vida de persistência obtido no presente trabalho foi duas vezes maior que aquele obtido por esse autor, quando o produto foi empregado na formulação concentrado emulsionāvel mais ōleo mineral. Possivelmente, essa diferença tenha sido devido às diferenças entre as variedades de laranjas e condições climáticas, que, segundo GUNTHER (1969) são fatores que afetam o comportamento dos residuos de pesticidas em frutas citricas.

Visto que os limites de tolerância para pesticidas em fru tas cỉtricas são estabelecidos com base na fruta toda (GUNTHER, 1969), 
nas amostragens de frutos realizados aos $17,24,34$ e 45 dias após a aplicação, foram anotados o peso total dos frutos e das cascas provenientes de cada amostra, a fim de se obter a porcentagem de casca no frutos da variedade de laranja Hamlin. Os resultados obtidos são mostrados na Tabela 7.

Atravēs desses resultados pode-se constatar que os frutos em estāgio de maturação possuem aproximadamente $26 \%$ de casca e obviamente $74 \%$ de polpa. Uma vez que não foram encontrados resĩduos nas polpas pelo método analïtico empregado, os resỉduos na fruta toda podem ser extrapolados multiplicando-se os residduos encontrados nas cascas pelo fator 0,26. Assim, nas dosagens empregadas dos produtos, 8 dias apōs a aplicação foi o espaço de tempo requerido para que o resíduo de fenitrothion baixasse a um valor inferior ao limite de tolerância estabelecido pelo Grupo de Trabalho GT-2 da C.N.N.P.A. com base na fruta toda. Para o caso do ethion, jā na primeira amostragem ( 3 dias apōs a aplicação) o nīvel de resíduo encontrado foi inferior ao limite de tolerância estabelecido.

Entretanto, este tempo observado de 8 dias para fenitrothion é resultante de apenas uma aplicação, na dosagem empregada. Se fossem realizadas duas ou mais aplicações, teoricamente os nîveis de residuos persistentes nas cascas dos frutos seriam maiores e o tempo requerido para que o limite de tolerāncia fosse atingido seria alterado . Por exemplo, se fossem efetuadas duas aplicações de Fol ithion 50 CE $(150 \mathrm{ml}$ do produto comercial/100 1), espaçadas 30 dias, tem-se que aos 20 dias apōs a segunda aplicação, o resîduo persistente na casca seria dado 
teoricamente pela soma dos resĩduos parciais provenientes das duas aplicações, ou seja, apōs 50 dias (1. aplicação) e 20 dias (2. aplicação), que pela anālise da Figura 12, corresponderiam a 0,68 e 0,86 ppm, respec tivamente. Assim, o valor 1,54 ppm seria então o nỉvel de resĩduo esperado nas cascas, o qual corresponde a $0,4 \mathrm{ppm}$ com base na fruta toda. Co mo este é o limite de tolerância estabelecido pela C.N.N.P.A. tem-se que neste caso particular, um espaço de tempo de 20 dias seria requerido para que 0 nỉvel de resīduo baixasse atē o limite de tolerância.

Este exemplo aplicado para ethion, na dosagem e formulação anteriormente mencionados, resulta em nỉveis de resĩduos ainda aquēm do limite de tolerância estabelecido pela C.N.N.P.A., ou seja, 2 ppm.

Outras extrapolações poderiam ser feitas com duas ou mais aplicações dos produtos a diferentes intervalos entre as aplicações. 
Tabela 7. Peso de cascas e polpas de amostras de laranjas Hamlin em estägio de maturação

\begin{tabular}{cccc}
\hline $\begin{array}{c}\text { Amostras } \\
\text { (16 frutos) }\end{array}$ & $\begin{array}{c}\text { Peso dos frutos } \\
\text { (gramas) }\end{array}$ & $\begin{array}{c}\text { Peso de cascas } \\
\text { (gramas) }\end{array}$ & $\begin{array}{c}\text { Porcentagem } \\
\text { de casca }\end{array}$ \\
\hline 1 & 2175 & 574 & 26,4 \\
2 & 2547 & 658 & 25,8 \\
3 & 2125 & 538 & 25,3 \\
4 & 2205 & 605 & 27,4 \\
5 & 2336 & 655 & 28,0 \\
6 & 2460 & 595 & 24,1 \\
7 & 2569 & 629 & 24,5 \\
8 & 2237 & 547 & 24,5 \\
9 & 2123 & 560 & 26,4 \\
10 & 2279 & 625 & 27,4 \\
11 & 2491 & 586 & 23,5 \\
12 & 2462 & 674 & 27,4 \\
13 & 1917 & 504 & 26,3 \\
14 & 2518 & 595 & 23,6 \\
15 & 2225 & 592 & 26,6 \\
16 & 1924 & 517 & 26,9 \\
17 & 2499 & 591 & 23,6 \\
18 & 2052 & 565 & 27,5 \\
19 & 1927 & 518 & 26,9 \\
20 & 2637 & 693 & 26,3 \\
21 & 2092 & 502 & 24,0 \\
22 & 2229 & 584 & 26,2 \\
23 & 2480 & 671 & \\
\hline & & & \\
\hline
\end{tabular}


6. CONCLUSOES

A anālise dos resultados obtidos, nas condições em que as investigações foram desenvolvidas, permite concluir que:

a) o método de anālise de resīduos desenvolvidos por MÖLLHOFF (1967), empregado no presente trabalho, mostra-se bastante adequado para a anālise de resỉduos de ethion e fenitrothion em cascas e polpas de laranjas Hamlin, permitindo a detecção de nîveis de resíduos de ethion até 0,01 ppm em cascas ou polpas. Para fenitrothion os limites de deteç̧ão são 0,05 e 0,02 ppm em cascas e polpas, respectivamente;

b) os residuos desses pesticidas, na parte comestivel dos frutos (polpa), após a aplicação dos produtos comerciais Ethiol 100 e Folithion $50 \mathrm{CE}$, são inferiores aos limites de deteçãa do mētodo analítico empregado, indicando que a casca funciona como uma barreira eficien te contra a penetração dos resíduos;

c) os valores de meia-vida de persistência desses produtos nas cascas dos frutos correspondem a 50 e 89 dias para ethion e fenitrothion, respectivamente, indicando que os residuos deste ūitimo 
56

são mais persistentes;

d) baseando-se nos resultados obtidos e nos limites de tolerância para esses produtos em frutas citricas estabelecidos pelo Gru po de Trabalho GT-2, da Comissão Nacional de Normas e Padrões para Alimentos - C.N.N.P.A., do Ministério da Saúde, os resĩduos de fenitrothion (com base na fruta toda) atingem o limite de tolerância $(0,4$ ppm) 8 dias após a aplicação enquanto os de ethion não são superiores ao limite de tolerância (2 ppm, com base na fruta toda) desde a primeira amostragem, ou seja, aos três dias apōs a aplicação. 


\section{SUMMARY}

The persistence of fenitrothion (Folithion $50 \mathrm{CE}$ ) and ethion (Ethiol 100: 10\% of ethion plus 68\% of emulsive oil) on and in citrus fruits was studied.

The experiment was set in a 7-year old orange orchard of the variety Haml in at the "Estação Experimental de Citricultura do Instituto Agronōmico de Campinas" - in Cordeirópolis, State of São Paulo, Brazil.

Haml in orange trees were sprayed at the rate of $400 \mathrm{ml}$ of Ethiol 100 in $100 \mathrm{l}$, or approximately $.68 \mathrm{ml}$ of a.j. per tree and $150 \mathrm{ml}$ of Folithion $50 \mathrm{CE}$ in $100 \mathrm{l}$ or approximately $1.275 \mathrm{ml}$ of a.i. per tree. Samples of 16 full-sized fruits each were collected at $3,10,17,24,34$, 45, 60 and 104-day intervals after spraying. Residues in the rind and in the pulp (edible portion) were determined separately.

The procedure used was adapted from MULLLHOFF (1967). The residues were extracted with acetone and purified by solvent partition with chloroform, clean-up was performed in a florisil (deactivated with 
$5 \%$ water) column and the elution proceeded with benzene. The purified extract was concentrated and injected in a CG gas chromatograph equiped with a 10\% DC-200 coated on silanized chromosorb W glass column, $180 \mathrm{~cm}$ in lenght and 1/8" i.d., and alkaly flame phosphorus detector (AFID).

The metodology used could detect residues of ethion as low as .01 ppm in the rind and pulp, and residues of fenitrothion as low as $.05 \mathrm{ppm}$ in the rind and $.02 \mathrm{ppm}$ in the pulp. The recovery from pulp and rind fortified extracts were $82-102 \%$ for fenitrothion and $92-104 \%$ for ethion.

Ethion and fenitrothion residues were not detected in the pulp of the fruits. The rind analysis showed that fenitrothion residues are more persistent than ethion, and half-life persistence values were 50 and 89 days for ethion and fenitrothion, respectively.

According to the official tolerances stablished by "Comissão Nacional de Normas e Padrões para Alimentos - Ministērio da Saūde", fenitrothion residues (in the whole fruit) were below the tolerance (.4 ppm) at 8-day interval after the application. Ethion residues (in the whole fruit) were below the tolerance (2 $\mathrm{ppm})$ since first sampling. 


\section{LITERATURA CITADA}

AMERICAN CHEMICAL SOCIETY, 1979. Chemicals remain strong in pest control. Chem.Eng.News, Washington, $57(3): 26$.

ANDERSON, C.A.; C.MAC DOUGALL; J.E.KESTERSON; T.HENDRICSON e R.F.BROOKS, 1963. The effect of processing on Guthion residues in orange and orange products. J.Agric. Food Chem., Washington, 11:422-423.

BLINN, R.C.; G.E.CARMAN; W.E.EWART e F.A.GUNTHER, 1959. Residual behavior of various insecticides on and in lemons and oranges. J.Econ.Entomol., College Park, 52(1):42-44.

BOWMAN, M.C. e M.BEROZA, 1969. Determination of Accothion, its oxygen analog, and its cresol in corn, gross, and milk by gas chromatography. J.Agric.Food Chem., Washington, 17(2):271-276.

BRASIL. Fundação Instituto Brasileiro de Geografia e Estatỉstica, 1977. Anuārio Estatīstico. 38:1-848.

CAVERO, E.S.; M.de S.GUERRA e C.P.D.da SILVEIRA, 1976. Manual de Inseticidas e Acaricidas. Pelotas, Editora Aimara Ltda., 345 p. 
DAWSON, J.A; L.DONEGAN e E.M.THAIN, 1964. The determination of paration and related insecticides by gas-liquid chromatography with special reference to fenitrothion residues in cocoa. Analyst, Cambridge, 89(1060):495-496.

DOROUGH, H.W.; N.M.RANDOLPH E G.M.WIMBISH, 1966. Residual nature of certain organophosphorous insecticides in grain sorghum and coastal Bermuda grass. Bull.Environ.Contam.Toxicol. I(2):46-58. Apud Chemical Abstracts, Columbus, 65(5):7894, 1966. [Ref. 7894a].

GALVAO, D.M. e E.A.PIRES coord., s.d. Tolerâncias e prazos de carēncia. In: Catālogo dos defensivos agrīcolas. Brasilia. Ministério da Agri cultura. cap. IX, p.63-98.

GOLAKA, J., 1971. Toxicological evaluation of some vegetables contaminated with fenitrothion, an insecticide used in plant cultivation.II. Dynamics of fenitrothion declive during the growth period. Bromatol. Chem.Toksykol. $4(1): 77-85$. Apud Chemical Abstracts, Columbus, $\underline{76}$ $(3): 103,1972$. [Ref. 11051].

GUNTHER, F.A., 1969. Insecticides residues in California citrus fruits and products. Residue Reviews. 28:1-127.

GUNTHER, F.A. e L.R.JEPPSON, 1954. Residues of p-chlorophenyl-p-chloroben zene-sulfonate (Compound $\mathrm{K}-6451$ ) on and in lemons and oranges. J.Écon. Entomol., College Park, 47: 1027-1032.

GUNTHER, F.A. e R.C.BLINN, 1955. Analys is of insecticides andacaricides. New York, London. Interscience, $696 \mathrm{p}$.

GUNTHER, F.A.; L.R.JEPPSON e G.B.WACKER, 1955. Persistence of chlorobenzilate residues in mature lemon fruits. J.Econ.Entomol., College Park, 48(4) : 372-374. 
GUNTHER, F.A. e R.C.BLINN, 1956. Persisting residues in plant materials. Ann.Rev. Entomol. Stanford, 1:167-180.

GUNTHER, F.A.; R.C.BLINN; L.R.JEPPSON; J.H.BARKLEY, 1957. Field persistance of the acaricide 4,4'-dichloro-alpha-(trichloro-methyl)-benzhydrol (F.W.293) on and in mature lemons and oranges. J.Agric.Food Chem., Washington, $\underline{5}(8): 595-598$.

GUNTHER, F.A.; G.E.CARMAN; L.R.JEPPSON; J.H.BARKLEY e R.C. BLINN, 1959. Residual behavior of $S-(p-c h l o r o p h e n y l t h i o)$ methyl 0,0-diethyl phosphorodithioate (Trithion) on and in mature lemons and oranges. $\quad$. Agric.Food Chem., Washington, $\underline{7}(1): 28-30$.

GUNTHER, F.A.; R.C.BLINN e G.E.CARMAN, 1962. Residues of ethion on and in lemons and oranges as determined by an infrared spectrophotometric procedure. J.Agric.Food Chem., Washington, 10(3):224-226.

IWATA, Y.; W.E.WESTLAKE; J.H.BARKLEY; G.E.CARMAN e F.A. GUNTHER, 1977. Behavior of phentoate (Cidial) deposits and residues on and in grapefruits, lemons and lemon leaves, orange and orange leaves, and in the soil beneath orange trees. J.Agric.Food Chem., Washington, $25(2): 362-368$.

LIPOWSKA, T.; KUBACKI, J.S. e GOSZCZ, H., 1975. Method for determining organophosphate pesticide residues in fruit and vegetable raw materials, by gas chromatography with a thermionic detector. Pr.Inst. Lab.Badaw.Przem. Spozyw 25(3):395-407. Apud Chemical Abstracts, Columbus, 85(23):389, 1976. [Ref. 175680].

LISKA, B.J. e N.J.STADELMAN, 1969. Effects of processing on pesticides in food. Residue Reviews, 29:61-72. 
LUKE, M.A.; J.E.FROBERG e H.T.MASUMOTO, 1975. Extraction and cleanup of organochlorine, organophosphate, organonitrogen, and hydrocarbon pesticides in procedure for determination by gas-liquid chromatography. J.Ass.0ff.Anal.Chem., Washington, 58(5):1020-1026.

MACNEIL, J.D. e HIKICHI, M. 1976. Degradation of endosulfan and ethion on pears and pear grape foliage. J.Agric.Food Chem., Washington, 24 (3): 608-611.

MÖLLHOFF, E., 1967. Determinaciōn gascromatogrāfica de residuos en plan tas y muestras de terrenos despuēs de la aplicaciōn de preparados de la serie E 605 y Agritox. Pflanzenschutz - Nachrichten "Bayer". 20 (2):589-606.

NAKANO, 0.; S.SILVEIRA NETO; G.C.de BATISTA; M.YOKOYAMA; N.DEGASPARI e L.C.MARCHINI, 1977. Manual de Inseticidas - Dicionārio. São Paulo, Agronómica Ceres Ltda., 272 p.

NELSON, R.C., 1964. Screening procedure for organophosphate pesticide residues on fruits and vegetables by microcoulometric gas chromatogra phy. J.Ass.Off.Anal.Chem., Washington, $47(2): 289-292$.

NELSON, R.C., 1965. Screening procedure for organophosphate pesticide residues on fruits and vegetables by microcoulometric gas chromatogra phy. J.Ass.Off.Anal.Chem., Washington, $48(4): 752-759$.

NELSON, R.C., 1967. Procedure for nine organophosphate pesticide residue on fruits and vegetables, using microcoulometric gas chromatography. J.Ass. Off.Anal.Chem., Washington, 50(4):922-926.

PARDUE, R.J., 1971. Recovery of organophosphorus compounds using the AOAC multiresidue method. J.Ass.Off.Anal.Chem., Washington, 54(2): 359-360. 
PATRASHKU, F.I., 1971. Dynamics of methylnitrophos, metathion, and Sumithion residues on the leaves, branches, and fruit of the apple tree under Moldavian conditions. Khim.Sel.Khoz. $\underline{9}(11): 835-837$. Apud Chemical Abstracts, Columbus, 76(15):117, 1972. [Ref. 82130].

PIGATI, P.; C.RIBAS; R.S.LONGO e L.ALVES, 1975. Residuos em cafē beneficiado colhido de cultura tratada com 0 inseticida ethion. In: Resumos 30 Congr.Bras.Pes.Cafeeiros. Curitiba, IBC-EMBRAPA, p. 41-42.

RANDALL, R.W.; R.W.STORHERR e J.R.PARDUE, 1969. Charcoal column cleanup Method for many organophosphorus pesticide residues in crop extracts. J.Ass.Off.Anal.Chem., Washington, $52(3): 522-526$.

RENVALL, S., 1976. Examination of phosphorous pesticides in fruits and vegetables. Var. Foeda 27(8-9):310-312. Apud Chemical Abstracts, Co lumbus, $84(15): 443,1976$. [Ref. 103918].

RIBAS, C., 1976. Estudo da persistência de residuos de lindane e endosulfan atravēs de cromatografia à gās, em grãos de café. Piracicaba, ESALQ/USP, 95 p. (Dissertação de Mestrado).

SISSONS, D.J. e G.M.TELLING, 1970. Rapid procedures for the routine determination of organophosphorus insectide residues in vegetables. I. Determination of hexane-soluble insecticides by gas-liquid chromatography and total phosphorus procedures. Journal of Chromatography, Amsterdam, 47:328-340.

STORHERR, R.W.; P.OTT E R.R.WATTS, 1971. A general method for organophosphorus pesticide residues in nonfatty foods. J.Ass.Off.Anal.Chem. Washington, $54(3): 513-524$. 
TASCHENBERG, E.F.; A.W.AVENS; G.M. PARSONS e S.D.GIBBS, 1963. Disappearance of spray deposits of DDT, Methoxychlor, Perthane, Ethion, and Diazinon from Concord grapes. J.Econ.Entomol., College Park, $\underline{56}$ (4) :431-438.

THOMPSON, J.F. ed., 1977. Analysis of pesticide residues in human and environmental samples; a compilation of methods selected for use in pesticide monitoring programs. Research Triangle Park, N.C., U.S. En vironmental Protection Agency. 1 v.

VERSINO, B.; M.-TH.van der VENNE e H.VISSERS, 1971. Comparison of some clenaup columns for residue analysis of chlorinated and phosphoruscontaining pesticides. J.Ass.0ff.Anal.Chem., Washington, 54(1):147149.

WESTLAKE, W.E.; F.A.GUNTHER e L.R.JEPPSON, 1970. Persistence of Azodrin residues on and in Valencia oranges and in laboratory-processed citrus pulp cattle feed. J.Agric. Food Chem., Washington, 18(5):864-865.

WESTLAKE, W.E.; F.A.GUNTHER e L.R.JEPPSON, 1971. Persistence of Omite residues on and in Navel oranges and lemons and in laboratory-processed citrus pulp cattle feed. J.Agric.Food Chem., Washington, 19(5): 894896.

ZWOLINSKA-SNIATALOVA, Z.; H.TROJANOWSKY, 1970. Studies on the residues of the preparation Folithion EC 50 to cabbage, using a gas chromatograph. Biul.Inst.0chr.Ros1. 47:315-24. Apud Chemical Abstracts, Columbus, 74(25):445, 1971 [Ref. 139980]. 